\title{
Repeatability of high-resolution 3D seismic data
}

\author{
Malin Waage ${ }^{1}$, Stefan Bünz ${ }^{1}$, Martin Landrø ${ }^{2}$, Andreia Plaza-Faverola ${ }^{1}$, and Kate A. Waghorn ${ }^{1}$
}

\begin{abstract}
High-resolution 4D (HR4D) seismic data have the potential for improving the current state-of-the-art in detecting shallow $(\leq 500-1000 \mathrm{~m}$ below seafloor) subsurface changes on a very fine scale (approximately 3-6 m). Time-lapse seismic investigations commonly use conventional broadband seismic data, considered low to moderate resolution in our context. We have developed the first comprehensive time -lapse analysis of high-resolution seismic data by assessing the repeatability of P-cable 3D seismic data (approximately 30-350 Hz) with short offsets and a high density of receivers. P-cable $3 \mathrm{D}$ seismic data sets have for decades been used to investigate shallow fluid flow and gas-hydrate systems. We analyze P-cable high-resolution 4D (HR4D) seismic data from three different geologic settings in the
\end{abstract}

Arctic Circle. The first two are test sites with no evidence of shallow subsurface fluid flow, and the third is an active seepage site. Using these sites, we evaluate the reliability of the P-cable 3D seismic technology as a time-lapse tool and establish a 4D acquisition and processing workflow. Weather, waves, tide, and acquisition-parameters such as residual shot noise are factors affecting seismic repeatability. We achieve reasonable quantitative repeatability measures in stratified marine sediments at two test locations. However, repeatability is limited in areas that have poor penetration of seismic energy through the seafloor, such as glacial moraines or rough surface topography. The 4D anomalies in the active seepage site are spatially restricted to areas of focused fluid flow and might likely indicate changes in fluid flow. This approach can thus be applied to detect migration of fluids in active leakage structures, such as gas chimneys.

\section{INTRODUCTION}

Seismic waves are sensitive to the amount and type of fluids, porepressure, and geomechanical properties of the material that they penetrate. When the physical properties in the subsurface vary in calendar time, they can be detected, monitored, and modeled by repeating seismic data sets (J. Williamson, personal communication, 2001; Ivanova et al., 2012; Nasser et al., 2016). For at least 20 years, time-lapse, or 4D, seismic surveys have been necessary for monitoring temperature, pore pressure, and fluid saturation in production-related hydrocarbon reservoirs and at $\mathrm{CO}_{2}$ storage sites (Landrø et al., 1999; Lumley, 2001; Chadwick et al., 2005; Johnston, 2013). Increasing demands for leakage control at onshore and subsea $\mathrm{CO}_{2}$ storage sites, monitoring of near-surface seasonal changes, earthquakes, or other types of geohazards (before and after) has furthermore caused an increase in the necessity of the method (Landrø and Amundsen, 2018).

The residual difference that is not related to physical property changes between a baseline survey (the first time-lapse survey acquired) and one or more seismic monitoring surveys (repeat surveys) affects the applicability of the time-lapse data and represents 4D seismic noise (Landrø, 1999; Vedanti and Sen, 2009). Positioning errors, varying tide and wave conditions, source and receiver variations, velocity changes in the water column, or processing differences are typical sources of 4D noise (Nasser et al., 2016). Geologically complex areas are more prone to $4 \mathrm{D}$ noise than areas with confined sedimentary beds lacking tectonic lineaments, folds, sharp erosional surfaces, etc. (Malme et al., 2005; Misaghi et al., 2007; Nasser et al., 2016). Monitoring systems and processing workflows are designed for the specific purpose of 4D data to minimize this residual difference (Nasser et al., 2016).

The magnitude of real detectable changes in physical properties depends on the minimum size of subsurface features resolved with the 3D seismic technology used, as well as the initial elastic properties of the reservoir. Unlithified sedimentary packages are favorable 4D seismic targets because the elastic property response to fluid

Manuscript received by the Editor 16 February 2018; revised manuscript received 10 September 2018; published ahead of production 31 October 2018; published online 21 December 2018.

${ }^{1}$ UiT the Arctic University of Norway, CAGE-Centre for Arctic Gas Hydrates, Environment and Climate, Department of Geosciences, Troms $\emptyset$ N-9037, Norway. E-mail: malin.waage@uit.no (corresponding author); stefan.bunz@uit.no; andreia.a.faverola@uit.no; kate.a.waghorn@uit.no.

${ }^{2}$ NTNU-Norwegian University of Science and Technology, Department of Electronic Systems, Trondheim7491, Norway. E-mail: martin.landro@ntnu.no.

(C) 2019 Society of Exploration Geophysicists. All rights reserved. 
change is higher than that of harder, more consolidated rocks. Better detectability of 4D seismic anomalies and less 4D seismic noise improves the overall 4D quality.

To date, marine 4D seismic surveys have been typically limited to conventional seismic frequencies (approximately 5-120 Hz) wellsuited for monitoring deep reservoirs. Extending the 4D bandwidth toward higher frequencies combined with higher vertical and lateral resolution enable more accurate separation of smaller features (better 4D detection), which will increase the reservoir monitoring resolution in the shallower seismic interval (Lecerf et al., 2015). Calvert (2005) states that in future 4D technology, detection of smaller changes will become an increasing demand.

The high-resolution 3D (HR3D) P-cable seismic system (approximately $30-350 \mathrm{~Hz}$ ) is conceived to produce data with a spatial resolution of 3-6 $\mathrm{m}$, surpassing the resolution of conventional 3D seismic by one order of magnitude (Planke et al., 2009; Planke, 2013). For more than a decade, the P-cable seismic system has been used to map shallow gas accumulations, gas hydrate systems, and fluid-flow structures, such as gas chimneys (Petersen et al., 2008; Crutchley et al., 2010; Plaza-Faverola et al., 2011; Bünz et al., 2012). In recent years, several client and multiclient P-cable surveys have been acquired in the Barents Sea and Norwegian continental shelf, contributing to, for example, discovery of the Peon gas field (Eriksen et al., 2014). In a 4D sense, time shifts (TSs) and changes in acoustic impedance on P-cable 3D seismic data can be assessed on an excellent resolution. It is, however, worth pointing out that the

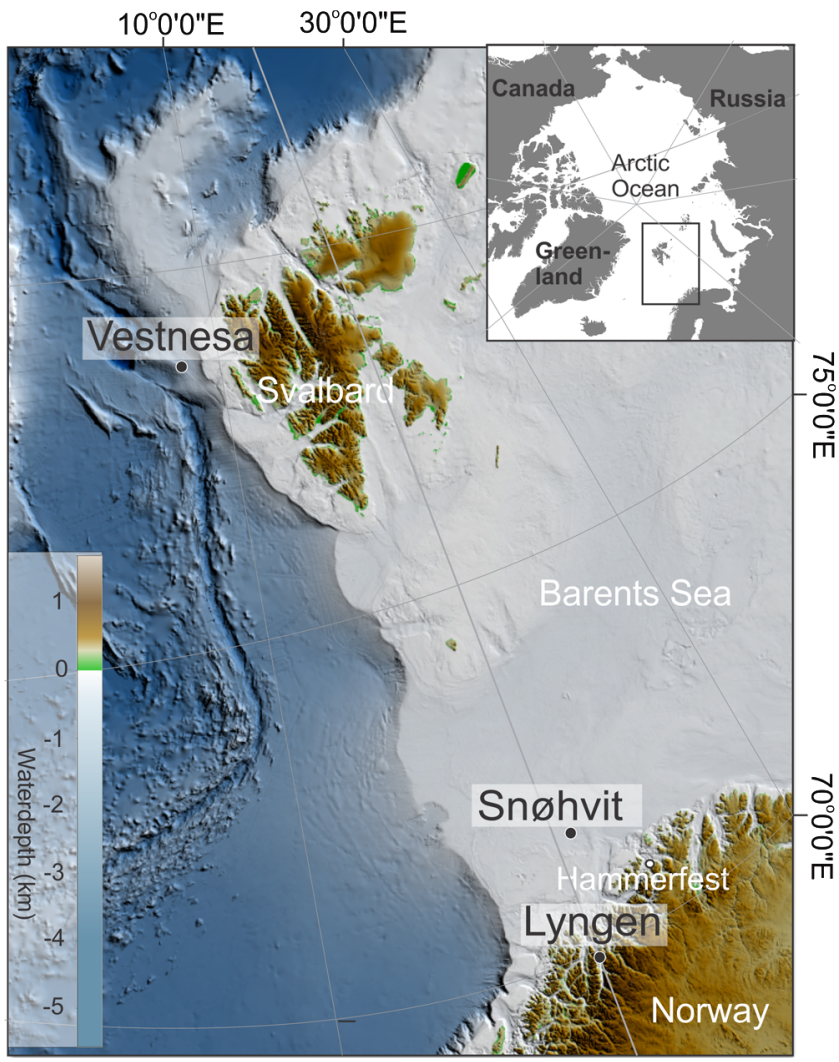

Figure 1. Overview map, showing the location of the different $\mathrm{P}$ cable seismic 4D survey sites, the Lyngen area, the Snøhvit area, and the Vestnesa ridge. short streamer length (25-100 m) of the P-cable seismic system limits seismic velocity and amplitude variation with offset analyses.

We investigate and discuss if and under what circumstances the high-resolution P-cable seismic technology is applicable as a 4D seismic monitoring tool. To cover many different geologic settings, weather conditions, and the robustness of the acquisition procedure, we have acquired a baseline and repeated surveys in three areas in the Arctic (Figure 1). We describe the 4D acquisition, preprocessing, and 4D processing methods implemented on the three study sites; and we present and evaluate schematic results of repeatability measures and seismic differences. All three sites offer different geologic conditions, whereby two of the sites (Lyngen and Snøhvit) are test sites where we do not expect any changes in the subsurface sediments (Hansen et al., 2011; Tasianas et al., 2016). The third site is the Vestnesa Ridge offshore Svalbard, a well-studied active fluid release and gas hydrate system in the Arctic. We discuss whether or to what extent 4D anomalies in the Vestnesa data can relate to natural subsurface changes and pore-fluid dynamics.

\section{STUDY AREAS}

\section{Test site 1: Lyngen area}

The P-cable data sets Lyngen 2012 and 2014 are acquired in the Lyngenfjord, a fjord in Northern Norway (Figure 1). The seafloor (380-440 ms two-way traveltime [TWT] (approximately $280-325 \mathrm{~m}$ ) is featureless and slightly dipping toward the margin of the fjord (Figure 2). The subsurface covered with the P-cable data represents a postglacial basin filled with mostly stratified sediments (unit 1) underlain by a distinct erosive contact reflecting a transition to moraine deposits (unit 2). Unit 1 is approximately $30-160 \mathrm{~m}$ thick (Figure 2). Within unit 2, two distinct moraine ridges occur at approximately60 $\mathrm{m}$ depth distance and appear as prominent, erosive, and undulating horizons (Figure 2).

\section{Test site 2: Snøhvit area}

Two P-cable data sets Snøhvit 2011 and 2013 are located in the Hammerfest basin area, $2 \mathrm{~km}$ south of the Snøhvit field in the western Barents Sea (Figure 1). Pockmarks and plow marks characterize an otherwise flat seafloor at approximately $440-470 \mathrm{~ms}$ TWT (approximately 335-352 m) below the sea surface (Figure 3). The seafloor pockmarks represent a record of previous fluid activity in the area; however, currently, there is no sign of any fluid release (Hansen et al., 2011; Tasianas et al., 2016). The 3D seismic data resolve the upper $225 \mathrm{~m}$ of the subsurface strata. The seismic can be divided into two main units separated by a distinctive, high-amplitude unconformable horizon - the upper regional unconformity (URU) that absorbs most of the seismic energy (Figure 3). The upper unit consists of glacial-related sediments characterized by seismically chaotic, weaker amplitude reflectors of subhorizontal to horizontal orientation. The lower unit comprises dipping reflection events between weaker amplitude chaotic thin beds of early-middle Cenozoic age (Tasianas et al., 2016). This unit is interrupted by faults with small $(<10 \mathrm{~m})$ displacements. For the $4 \mathrm{D}$ analysis, we divide the subsurface into two depth intervals of similar thicknesses. Interval 1 is located between 440 and $590 \mathrm{~ms}$ TWT (covering mostly the glacial unit), and interval 2 is located between 590 and $740 \mathrm{~ms}$ TWT (covering most of the underlying dipping strata). 


\section{Vestnesa ridge}

Vestnesa ridge is a large sediment drift with an approximately $5 \mathrm{~km}$ thick stratified sedimentary sequence located in 1200-1500 m water depth, extending from the western Svalbard continental slope toward the Molloy Ridge (Eiken and Hinz, 1993) (Figure 1). The site hosts an active fluid-flow system with evidence of past and present-day gas seepage (Petersen et al., 2010; Bünz et al., 2012; Panieri et al., 2017; Sztybor and Rasmussen, 2017; Knies et al., 2018). We carried out the 4D seismic study (seafloor depth approximately $1230-1250 \mathrm{~m}$ ) in an area of five large seafloor pockmarks (up to $700 \mathrm{~m}$ in diameter and $10 \mathrm{~m}$ deep) and underlying vertical fluid flow structures, so-called chimneys (Figure 4). Multiyear echo-sounder surveys detected active gas seepage from three of these pockmarks (called Lomvi, Lunde, and Torsk) (Smith et al., 2014; Panieri et al., 2017).

The seismic data show horizontal to subhorizontal strata interrupted by focused subvertical fluid-flow features (Figure 4). These chimneys show a high variability in their seismic signatures with alternating blanked areas and high-amplitude anomalies related to fluid perturbations and the presence of gas hydrates/authigenic carbonates (Petersen et al., 2010; Panieri et al., 2017). The chimneys pierce through a high-amplitude reversed-polarity reflection
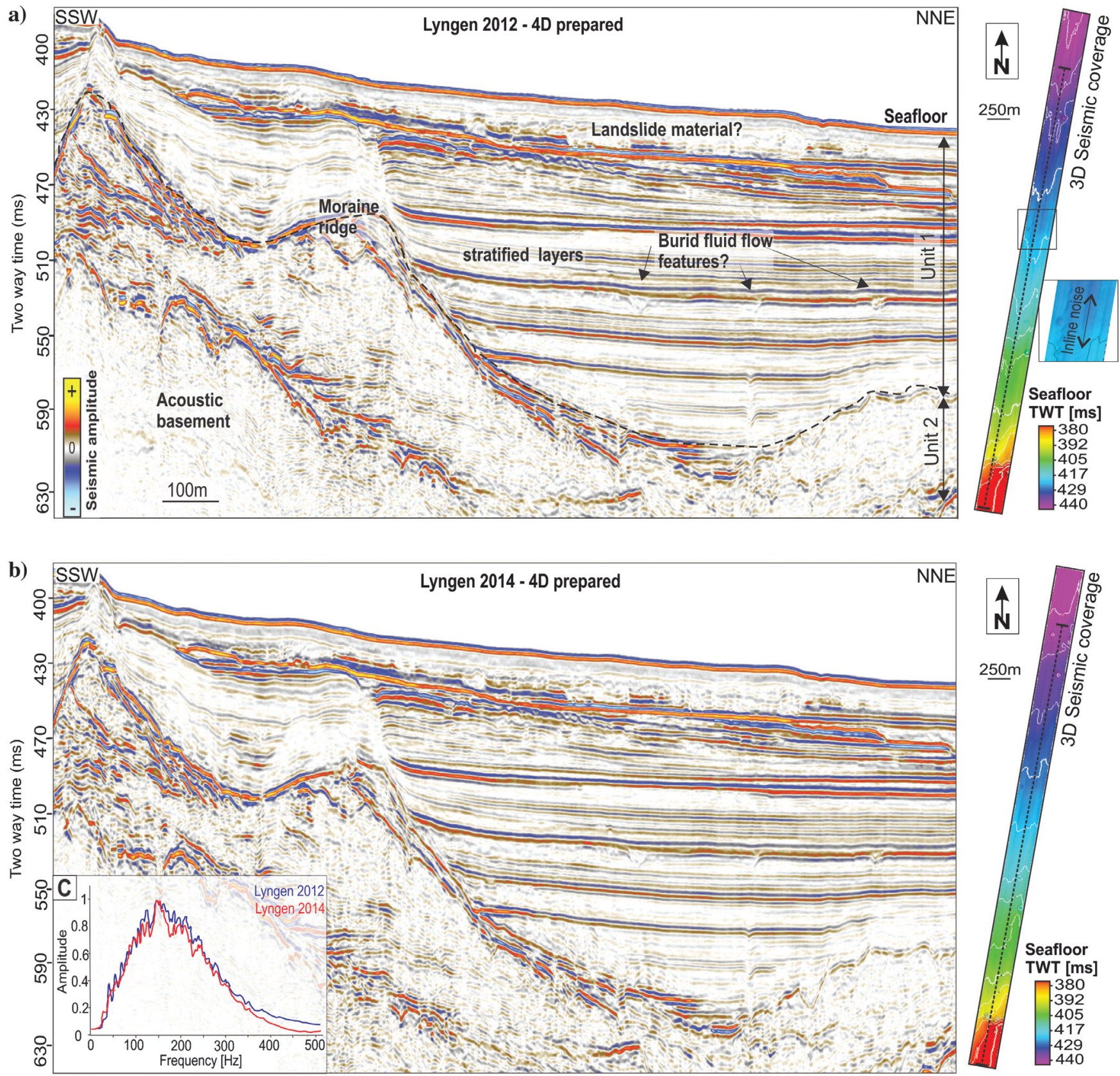

Figure 2. Seismic bathymetry (indicating seismic coverage) and inline example of the Lyngen 2012 and 2014 data. (a) Lyngen 2012 (baseline) and (b) Lyngen 2014 (monitor). (c) Amplitude spectra of the two data sets. The main geologic features are shown in (a). 
approximately $1900 \mathrm{~ms}$ TWT interpreted as a gas-hydrate-related bottom-simulating reflector (BSR) (Bünz et al., 2012) (Figure 4).

\section{METHODS}

\section{Seismic repeatability}

Seismic repeatability relates to how accurate a survey is repeated in calendar time. Several 4D attribute measures can quantify repeatability (Kragh and Christie, 2002; Liu et al., 2009):

- TS: The time difference between two traces $a$ and $b$, where the squared difference in amplitude is minimum.
- Crosscorrelation $\left(x\right.$ cor $\left./ \varnothing_{a b}\right)$ : It is the crosscorrelation between traces $a_{i}$ and $b_{i}$ within time window $t_{1}-t_{2}$.

- Predictability (PRED): The percentage of the summed square crosscorrelation within a time window divided by the summed product of the autocorrelations.

- $\quad$ Normalized root mean square ( $\mathrm{Nrms})$ : The percentage normalized rms difference of traces from two surveys.

$$
\varnothing_{a b}=\frac{\sum_{i=t-w / 2}^{t+w / 2} a_{i} b_{i}}{\sqrt{ } \sum_{i=t-w / 2}^{t+w / 2} a_{i}^{2} \sum_{i=t-w / 2}^{t+w / 2} b_{i}^{2}},
$$

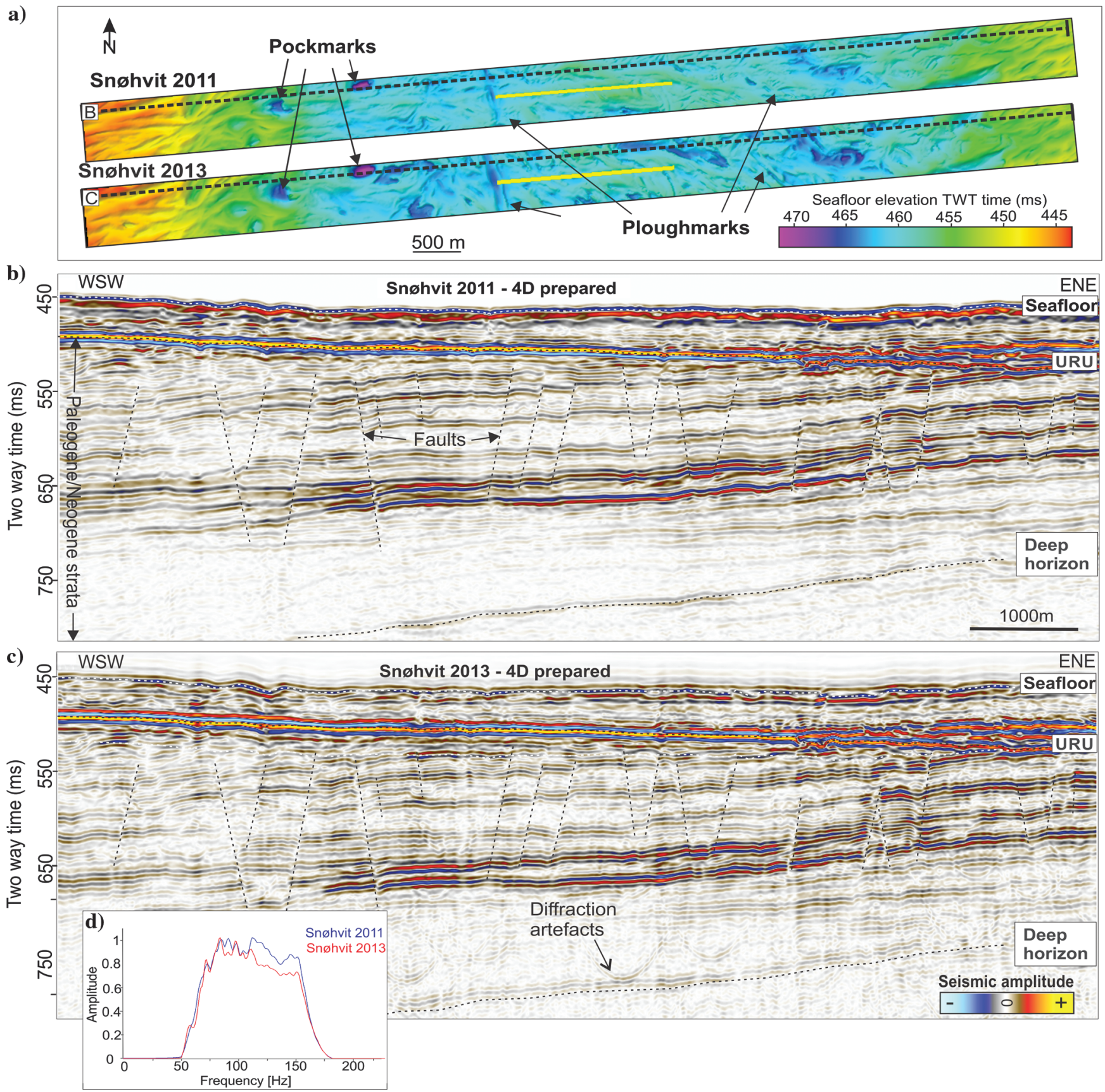

Figure 3. An overview of the Snøhvit 3D seismic data.(a) Seismic bathymetry of the two data sets, (b) seismic inline example of Snøhvit 2011 (baseline), and (c) seismic inline example of Snøhvit 2013 data (monitor). (d) Amplitude spectra of the two data sets. 


$$
\begin{gathered}
\text { PRED }=\frac{100 \times \sum \varnothing_{a b}(\tau) \times \varnothing_{a b}(\tau)}{\sum \varnothing_{a a}(\tau) \times \varnothing_{b b}(\tau)}, \\
N \mathrm{rms}=2 \frac{\mathrm{rms}(\text { baseline }- \text { monitor })}{\mathrm{rms}(\text { baseline })+\text { rms }(\text { monitor })} .
\end{gathered}
$$

The rms operator is defined as

$$
\operatorname{rms}\left(a_{i}\right)=\sqrt{\frac{1}{N} \sum_{i_{1}}^{i^{2}}\left(a_{i}\right)^{2}}
$$

where $N$ is the number of samples $a_{t}$ in the interval $t_{1}-t_{2}$, and $i_{1}$ and $i_{2}$ represent the time-sample number for $t_{1}$ and $t_{2}$.

The crosscorrelation and predictability measure range from 0 to 1 (or $0 \%$ to $100 \%$ ) and are sensitive to noise and changes in the earth's reflectivity, but they are insensitive to amplitude, static, and phase changes (Kragh and Christie, 2002). Thus, if both traces anticorrelate, the predictability and crosscorrelation is one, or if the amplitude of the trace is half the amplitude of the other, it is still one. Nrms is susceptible to all changes in the data and range between 0 and $2(0 \%-200 \%)$. Random noise contributes to increasing this $4 \mathrm{D}$ measure. If both $4 \mathrm{D}$ surveys contain random noise, the measure is approximately 1.41. If they are phase-reversed compared to each other, the value will be approximately 2 .

\section{D seismic acquisition}

The P-cable system (Figure 5) is an HR3D seismic acquisition system that can tow up to 18 short streamers $(25-100 \mathrm{~m})$ with short streamer spacing $(6.25-12.5 \mathrm{~m})$ resulting in dense common midpoint (CMP) coverage with small bin sizes as low as $3.125 \mathrm{~m}$ (Planke et al., of $3 \mathrm{~s}$, and Vestnesa 2013 with a shot interval of $5 \mathrm{~s}$ (sail line 1-4) and $6 \mathrm{~s}$ (sail line 5-30). The difference in the shooting interval for the Vestnesa 2013 data set is due to problems with airgun pressure supplied from the compressor.

c)
2009; Petersen et al., 2010). The time-lapse data
sets used in this study were acquired using
14 streamers of 25 m length and $12.5 \mathrm{~m}$ streamer
spacing. Each streamer contains eight receivers
with a group interval of $3.125 \mathrm{~m}$.
All data sets are acquired using one mini-GI
air gun with an injector/generator volume of
15/15 in $^{3}$ operated in harmonic mode with an
air-gun pressure of 160 bar (Lyngen and Snøhvit)
and 170 bar (Vestnesa). The Lyngen 2012 ,
Snøhvit (2011 and 2013 ), and Vestnesa 2012 sur-
veys were operated with a 4 s shot interval,

2009; Petersen et al., 2010). The time-lapse data
sets used in this study were acquired using
14 streamers of 25 m length and $12.5 \mathrm{~m}$ streamer
spacing. Each streamer contains eight receivers
with a group interval of $3.125 \mathrm{~m}$.
All data sets are acquired using one mini-GI
air gun with an injector/generator volume of
15/15 in $^{3}$ operated in harmonic mode with an
air-gun pressure of 160 bar (Lyngen and Snøhvit)
and 170 bar (Vestnesa). The Lyngen 2012 ,
Snøhvit (2011 and 2013 ), and Vestnesa 2012 sur-
veys were operated with a 4 s shot interval,

2009; Petersen et al., 2010). The time-lapse data
sets used in this study were acquired using
14 streamers of 25 m length and $12.5 \mathrm{~m}$ streamer
spacing. Each streamer contains eight receivers
with a group interval of $3.125 \mathrm{~m}$.
All data sets are acquired using one mini-GI
air gun with an injector/generator volume of
15/15 in $^{3}$ operated in harmonic mode with an
air-gun pressure of 160 bar (Lyngen and Snøhvit)
and 170 bar (Vestnesa). The Lyngen 2012 ,
Snøhvit (2011 and 2013 ), and Vestnesa 2012 sur-
veys were operated with a 4 s shot interval,

2009; Petersen et al., 2010). The time-lapse data
sets used in this study were acquired using
14 streamers of 25 m length and $12.5 \mathrm{~m}$ streamer
spacing. Each streamer contains eight receivers
with a group interval of $3.125 \mathrm{~m}$.
All data sets are acquired using one mini-GI
air gun with an injector/generator volume of
15/15 in $^{3}$ operated in harmonic mode with an
air-gun pressure of 160 bar (Lyngen and Snøhvit)
and 170 bar (Vestnesa). The Lyngen 2012 ,
Snøhvit (2011 and 2013 ), and Vestnesa 2012 sur-
veys were operated with a 4 s shot interval,

2009; Petersen et al., 2010). The time-lapse data
sets used in this study were acquired using
14 streamers of 25 m length and $12.5 \mathrm{~m}$ streamer
spacing. Each streamer contains eight receivers
with a group interval of $3.125 \mathrm{~m}$.
All data sets are acquired using one mini-GI
air gun with an injector/generator volume of
15/15 in $^{3}$ operated in harmonic mode with an
air-gun pressure of 160 bar (Lyngen and Snøhvit)
and 170 bar (Vestnesa). The Lyngen 2012 ,
Snøhvit (2011 and 2013 ), and Vestnesa 2012 sur-
veys were operated with a 4 s shot interval,

2009; Petersen et al., 2010). The time-lapse data
sets used in this study were acquired using
14 streamers of 25 m length and $12.5 \mathrm{~m}$ streamer
spacing. Each streamer contains eight receivers
with a group interval of $3.125 \mathrm{~m}$.
All data sets are acquired using one mini-GI
air gun with an injector/generator volume of
15/15 in $^{3}$ operated in harmonic mode with an
air-gun pressure of 160 bar (Lyngen and Snøhvit)
and 170 bar (Vestnesa). The Lyngen 2012 ,
Snøhvit (2011 and 2013 ), and Vestnesa 2012 sur-
veys were operated with a 4 s shot interval,

2009; Petersen et al., 2010). The time-lapse data
sets used in this study were acquired using
14 streamers of 25 m length and $12.5 \mathrm{~m}$ streamer
spacing. Each streamer contains eight receivers
with a group interval of $3.125 \mathrm{~m}$.
All data sets are acquired using one mini-GI
air gun with an injector/generator volume of
15/15 in $^{3}$ operated in harmonic mode with an
air-gun pressure of 160 bar (Lyngen and Snøhvit)
and 170 bar (Vestnesa). The Lyngen 2012 ,
Snøhvit (2011 and 2013 ), and Vestnesa 2012 sur-
veys were operated with a 4 s shot interval,

2009; Petersen et al., 2010). The time-lapse data
sets used in this study were acquired using
14 streamers of 25 m length and $12.5 \mathrm{~m}$ streamer
spacing. Each streamer contains eight receivers
with a group interval of $3.125 \mathrm{~m}$.
All data sets are acquired using one mini-GI
air gun with an injector/generator volume of
15/15 in $^{3}$ operated in harmonic mode with an
air-gun pressure of 160 bar (Lyngen and Snøhvit)
and 170 bar (Vestnesa). The Lyngen 2012 ,
Snøhvit (2011 and 2013 ), and Vestnesa 2012 sur-
veys were operated with a 4 s shot interval,

2009; Petersen et al., 2010). The time-lapse data
sets used in this study were acquired using
14 streamers of 25 m length and $12.5 \mathrm{~m}$ streamer
spacing. Each streamer contains eight receivers
with a group interval of $3.125 \mathrm{~m}$.
All data sets are acquired using one mini-GI
air gun with an injector/generator volume of
15/15 in $^{3}$ operated in harmonic mode with an
air-gun pressure of 160 bar (Lyngen and Snøhvit)
and 170 bar (Vestnesa). The Lyngen 2012 ,
Snøhvit (2011 and 2013 ), and Vestnesa 2012 sur-
veys were operated with a 4 s shot interval,

2009; Petersen et al., 2010). The time-lapse data
sets used in this study were acquired using
14 streamers of 25 m length and $12.5 \mathrm{~m}$ streamer
spacing. Each streamer contains eight receivers
with a group interval of $3.125 \mathrm{~m}$.
All data sets are acquired using one mini-GI
air gun with an injector/generator volume of
15/15 in $^{3}$ operated in harmonic mode with an
air-gun pressure of 160 bar (Lyngen and Snøhvit)
and 170 bar (Vestnesa). The Lyngen 2012 ,
Snøhvit (2011 and 2013 ), and Vestnesa 2012 sur-
veys were operated with a 4 s shot interval,

2009; Petersen et al., 2010). The time-lapse data
sets used in this study were acquired using
14 streamers of 25 m length and $12.5 \mathrm{~m}$ streamer
spacing. Each streamer contains eight receivers
with a group interval of $3.125 \mathrm{~m}$.
All data sets are acquired using one mini-GI
air gun with an injector/generator volume of
15/15 in $^{3}$ operated in harmonic mode with an
air-gun pressure of 160 bar (Lyngen and Snøhvit)
and 170 bar (Vestnesa). The Lyngen 2012 ,
Snøhvit (2011 and 2013 ), and Vestnesa 2012 sur-
veys were operated with a 4 s shot interval,

2009; Petersen et al., 2010). The time-lapse data
sets used in this study were acquired using
14 streamers of 25 m length and $12.5 \mathrm{~m}$ streamer
spacing. Each streamer contains eight receivers
with a group interval of $3.125 \mathrm{~m}$.
All data sets are acquired using one mini-GI
air gun with an injector/generator volume of
15/15 in $^{3}$ operated in harmonic mode with an
air-gun pressure of 160 bar (Lyngen and Snøhvit)
and 170 bar (Vestnesa). The Lyngen 2012 ,
Snøhvit (2011 and 2013 ), and Vestnesa 2012 sur-
veys were operated with a 4 s shot interval,

2009; Petersen et al., 2010). The time-lapse data
sets used in this study were acquired using
14 streamers of 25 m length and $12.5 \mathrm{~m}$ streamer
spacing. Each streamer contains eight receivers
with a group interval of $3.125 \mathrm{~m}$.
All data sets are acquired using one mini-GI
air gun with an injector/generator volume of
15/15 in ${ }^{3}$ operated in harmonic mode with an
air-gun pressure of 160 bar (Lyngen and Snøhvit)
and 170 bar (Vestnesa). The Lyngen 2012,
Snøhvit (2011 and 2013 ), and Vestnesa 2012 sur-
veys were operated with a 4 s shot interval,
whereas Lyngen 2014 differs with a shot interval

For each of the sites, the planned acquisition lines and survey geometry of repeat surveys were identical to baseline surveys. Global positioning system devices were located on the gun and both paravanes. The positioning of streamers was calculated through a catenary line equation, and the offset was updated using the direct arrival time for each trace (Crutchley et al., 2011). Towing depth, navigational control, and weather conditions were assessed continuously. Despite that, potential deviations in the tracking system of the vessel and sea currents might affect the streamer array causing discrepancies of source-receiver geometry from survey to survey. Operational ship speed was typically four knots. An overview of the different survey parameters is listed in Table 1.

The two investigated P-cable data sets from the Lyngen area (2012 and 2014) have an overlap of $3.3 \mathrm{~km}^{2}$ (Table 1). The weather
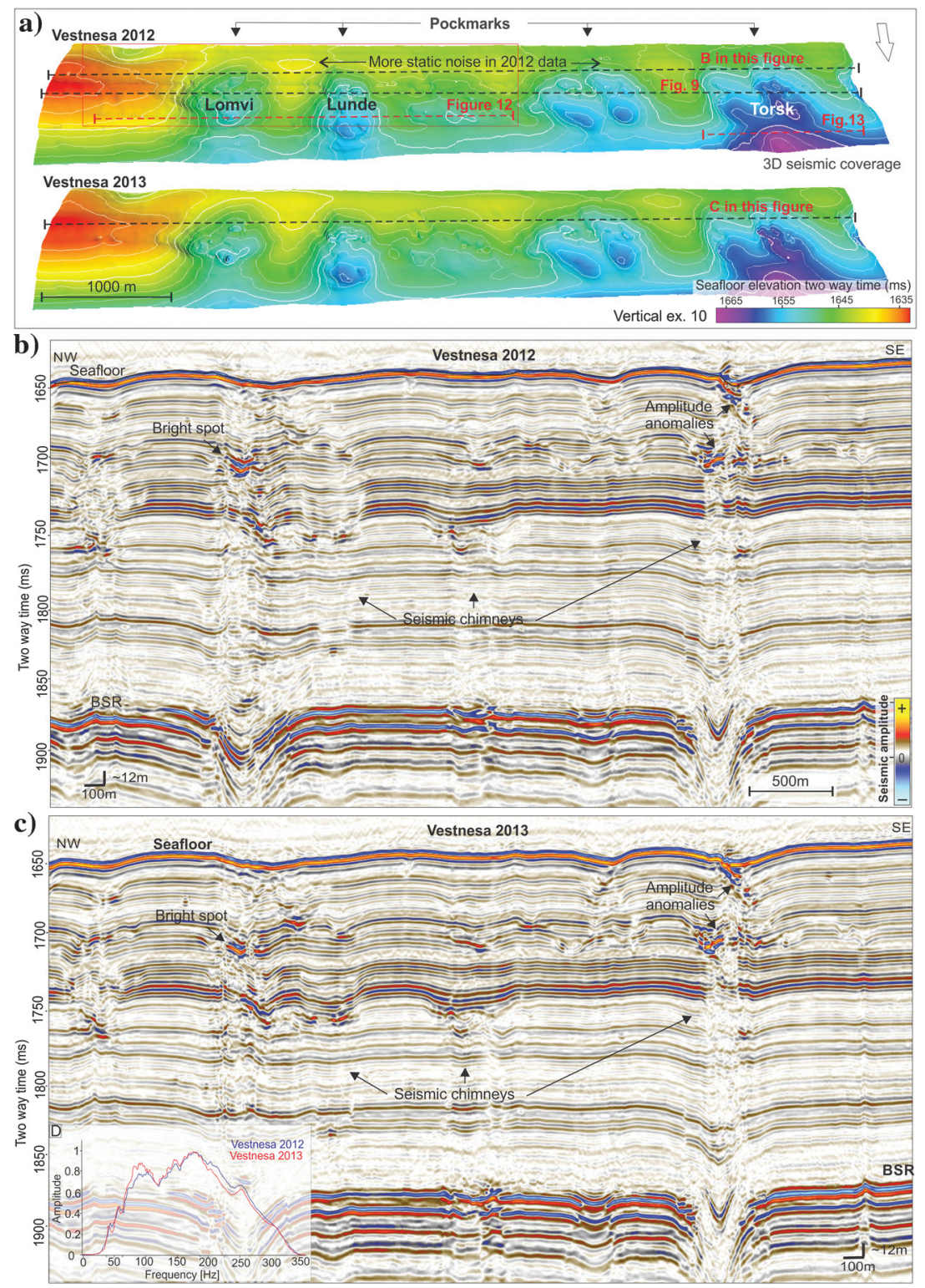

Figure 4. P-cable 3D seismic data volumes acquired on the Vestnesa Ridge in 2012 (above) and 2013 (below). (a) The seismic seafloor with the active pockmarks marked with their names. (b) The Vestnesa 2012 (baseline) and (c) the Vestnesa 2013 data (monitor). (d)The amplitude spectrum of both data sets. 
conditions were less favorable in 2012 , with $5-12 \mathrm{~m} / \mathrm{s}$ recorded wind speed as opposed to $0-3 \mathrm{~m} / \mathrm{s}$ during the acquisition in 2014 . The data sets in the Snøhvit area (2011 and 2013) overlap by an area of $2.4 \mathrm{~km}^{2}$. The weather and water temperature were comparable during both surveys with wind speeds of $6-8 \mathrm{~m} / \mathrm{s}$ in 2011 and $6-12 \mathrm{~m} / \mathrm{s}$ in 2013 . The data sets (2012 and 2013) from Vestnesa Ridge overlap by an area of approximately $10.7 \mathrm{~km}^{2}$. The weather was slightly worse in 2012 with winds of $4-12 \mathrm{~m} / \mathrm{s}$ compared with $1-7 \mathrm{~m} / \mathrm{s}$ in 2013.

\section{D seismic processing}

We conducted the 3D seismic processing sequence of the different data sets side-by-side using RadexPro software. The processing included removal of bad channels, geometry assignment, tide corrections, compensation for amplitude loss (spherical divergence), band-pass filter, 3D binning at $6.25 \times 6.25 \mathrm{~m}$ and normal moveout (NMO) correction, mean stack, and 3D Stolt migration using a constant average water velocity (Table 2). Processing parameters for each data set are listed in Table 1. Processes involving data-dependent operators were not applied.
Band-pass filter was chosen after inspection of the dominant frequency and frequency content of the different time-lapse data sets. The Lyngen 2012 and 2014 (25-35-300-400 Hz) showed comparable amplitude spectra with a common dominant frequency of $150 \mathrm{~Hz}$ (Figure 2).The Snøhvit time-lapse data sets showed a dominant frequency of $100 \mathrm{~Hz}$ with most spectral energy between 50 and $180 \mathrm{~Hz}$ (Figure 3). Consequently, we applied a relatively narrow frequency filter $(50-70-150-180 \mathrm{~Hz})$ for the $4 \mathrm{D}$ analysis. The Vestnesa 2012 and 2013 (30-50-275-350 Hz) showed comparable amplitude spectra with a dominant frequency of $175 \mathrm{~Hz}$ (Figure 4). Furthermore, we analyzed repeatability in three additional bandwidths of the Lyngen data: the low-mid case $(25-35-175-230 \mathrm{~Hz})$, mid case (50-70-175-230 Hz), and narrow case (50-70-140$180 \mathrm{~Hz})$ to investigate the seismic repeatability for different frequency intervals.

Signal-to-noise ratios (S/Ns) of the different surveys (Table 4) were estimated as the ratio between the average rms value of nonmuted stack beneath the seafloor in a $100 \mathrm{~ms}$ time window and the same time window of the water column. This is a practical way to estimate the $\mathrm{S} / \mathrm{N}$, but it is not accurate because the noise is measured in a window above the target zone. Due to the signal decay with

\section{Survey configuration:}

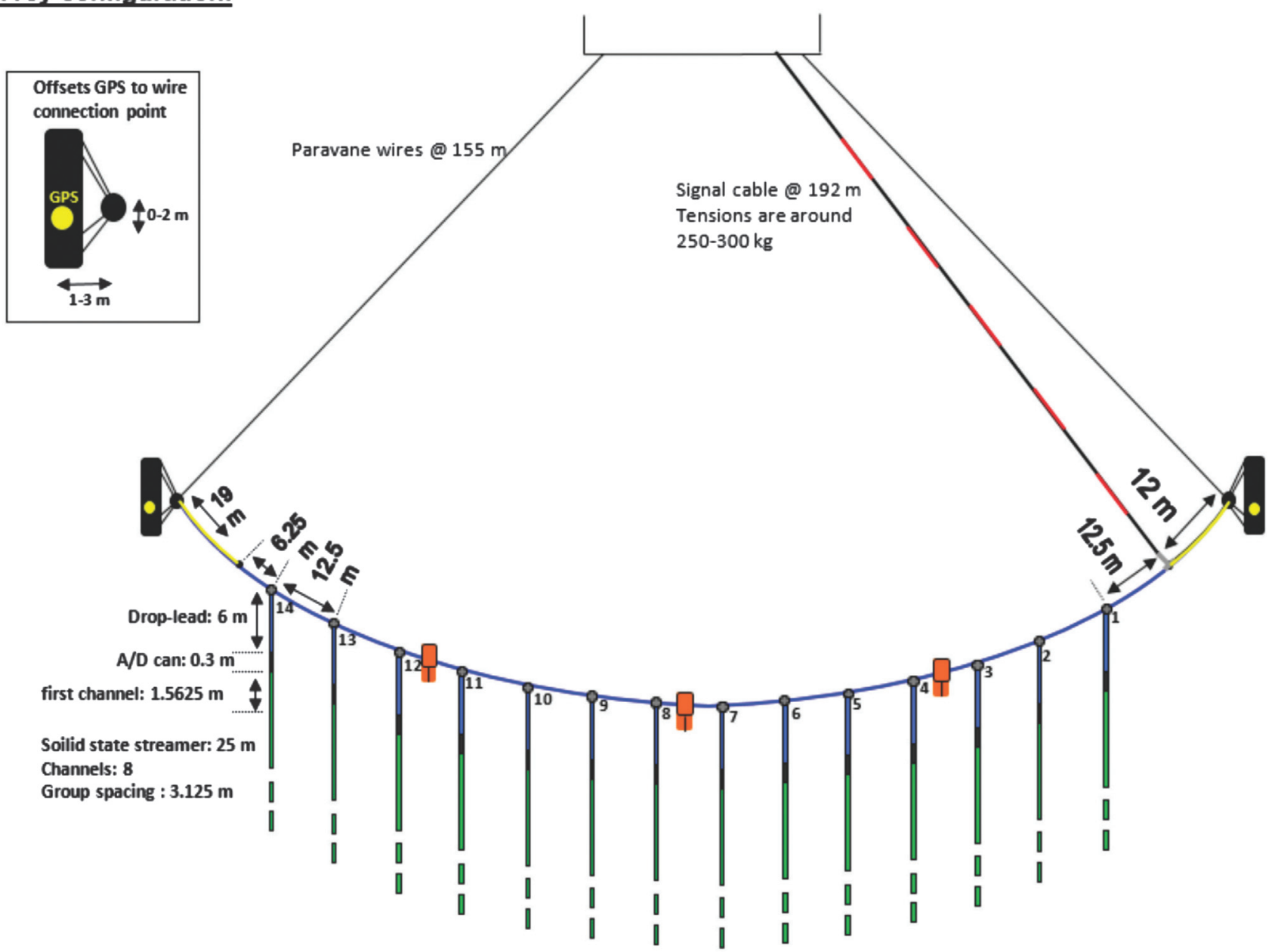

Figure 5. Schematic diagram of the P-cable 3D seismic system (Petersen et al., 2010). We use 14 streamers attached to a cross cable, spanned by two paravanes and towed perpendicular to the sail direction. 
time, the $\mathrm{S} / \mathrm{N}$ decreases with depth, as probably reflected in the differences between the Lyngen and Vestnesa $\mathrm{S} / \mathrm{N}$.

\section{D preprocessing}

The preparation of the 4D seismic data included standard 4D preprocessing steps, such as cutting seismic volume to a common coverage and creating common CMP numbers, CMP coordinates, and inline and crossline numbers. In addition, we implemented preprocessing steps to reduce residual difference and improve repeatability between the data sets. Random, incoherent, and coherent noise was suppressed in GeoTeric's poststack noise cancellation algorithms (including a structurally oriented and edge-preserving finiteimpulse response median hybrid filter and a tensor diffusion algorithm [TDiffusion]). Furthermore, we applied a small bulk shift static correction and a phase reversal if necessary, and we scaled amplitudes to a common average level (Table 2).

\section{Seismic 4D processing}

The 4D processing was carried out through five processing steps (Table 2) using a standard 4D calibration workflow in HRS Pro4D software. We briefly describe the application of the different steps in Table 3. Guided by time (TS), crosscorrelation (XC) thresholds, and a correlation window, the workflow intends to correct for misalignments in phase, time, seismic amplitude, and frequency between the base and monitor surveys. The thresholds were chosen after inspection of apparent TS and crosscorrelation values between the surveys. The correlation window was typically chosen globally, i.e., from the seafloor until reflections become too weak to indicate any geologic features or, for the Vestnesa case, between the seafloor (at approximately 1640 and $1840 \mathrm{~ms}$ TWT) and right above the BSR. This window is what we refer to as "average." Otherwise, we chose a shallow correlation window (50-150 ms) when correcting for static changes (step 3).

There is a small spatially consistent time (depth) variant shift $(<1 \mathrm{~ms})$ between the baseline and the monitor surveys in all case studies, which appears when comparing the TS of the upper and lower intervals. This consistent time-variant shift can result from a slight NMO stretch due to an incorrect velocity model and use of the Stolt 3D migration that seems to induce some stretch. It is important to stress, however, that the stretch is minor, but due to the high-frequency content, it is significant to reduce seismic similarity and repeatability measures. Processing step (5) (the timevariant shift) is usually attributed to correct for velocity variations in the overburden. Under strict thresholds (TS: $1 \mathrm{~ms}$, crosscorrelation: 90\%), we used this method to correct for the acquisition/ processing related nonstationary TS.

\section{RESULTS}

The 4D processing flow and step-wise results for the three case studies are presented in Figures 6, 7 (Lyngen), 8 (Snøhvit), and 9 (Vestnesa). Each process improved repeatability measures ( $\mathrm{Nrms}$, time and phase shifts, and crosscorrelation) and reduced seismic differences (Table 2), with some exceptions. Step 4 (rms scaling)

Table 1. Acquisition, 3D processing, and weather data of the three case studies.

\begin{tabular}{|c|c|c|c|c|c|c|c|}
\hline & & \multicolumn{2}{|c|}{ Lyngen } & \multicolumn{2}{|c|}{ Snøhvit } & \multicolumn{2}{|c|}{ Vestnesa } \\
\hline & & 2012 & 2014 & 2011 & 2013 & 2012 & 2013 \\
\hline \multirow{7}{*}{$\begin{array}{l}\text { Acquisition } \\
\text { information }\end{array}$} & Acquisition lines & 15 & 13 & 30 & 19 & 25 & 25 \\
\hline & Geometry deviation & $<5 \mathrm{~m}$ & $<5 \mathrm{~m}$ & $<5 \mathrm{~m}$ & $<5 \mathrm{~m}$ & $<5 \mathrm{~m}$ & $<5 \mathrm{~m}$ \\
\hline & Gun system & $\begin{array}{c}\text { Mini-GI } \\
\left(15 / 15 \text { in }^{3}\right)\end{array}$ & $\begin{array}{c}\text { Mini-GI } \\
\left(15 / 15 \text { in }^{3}\right)\end{array}$ & $\begin{array}{c}\text { Mini-GI } \\
\left(15 / 15 \text { in }^{3}\right)\end{array}$ & $\begin{array}{c}\text { Mini-GI } \\
\left(15 / 15 \mathrm{in}^{3}\right)\end{array}$ & $\begin{array}{c}\text { Mini-GI } \\
\left(15 / 15 \text { in }^{3}\right)\end{array}$ & $\begin{array}{c}\text { Mini-GI } \\
\left(15 / 15 \mathrm{in}^{3}\right)\end{array}$ \\
\hline & Shooting pressure & 160 bar & 160 bar & $160 \mathrm{bar}$ & 160 bar & 170 bar & 170 bar \\
\hline & Shooting interval & $4 \mathrm{~s}$ & $3 \mathrm{~s}$ & $4 \mathrm{~s}$ & $4 \mathrm{~s}$ & $4 \mathrm{~s}$ & $5-6 \mathrm{~s}$ \\
\hline & Streamer depth & $1-2 \mathrm{~m}$ & $1-2 \mathrm{~m}$ & $1-2 \mathrm{~m}$ & $1-2 \mathrm{~m}$ & $1-2 \mathrm{~m}$ & $1-2 \mathrm{~m}$ \\
\hline & $\begin{array}{c}\text { Weather } \\
\text { (wind, water } \\
\text { temperature) }\end{array}$ & $\begin{array}{c}5-12 \mathrm{~m} / \mathrm{s} \\
\text { form } \mathrm{W}-\mathrm{SW} \text {, } \\
0-4{ }^{\circ} \mathrm{C}\end{array}$ & $\begin{array}{c}0-3 \mathrm{~m} / \mathrm{s} \\
\text { form } \mathrm{S} . \\
\text { Calm sea }\end{array}$ & $\begin{array}{c}6-8 \mathrm{~m} / \mathrm{s} \\
\sim 7.3^{\circ} \mathrm{C}\end{array}$ & $\begin{array}{c}6-12 \mathrm{~m} / \mathrm{s} \\
\sim 10^{\circ} \mathrm{C}\end{array}$ & $\begin{array}{c}4-12 \mathrm{~m} / \mathrm{s} \\
0-4{ }^{\circ} \mathrm{C}\end{array}$ & $\begin{array}{c}1.4-7 \mathrm{~m} / \mathrm{s} \\
5.5-6.5^{\circ} \mathrm{C}\end{array}$ \\
\hline \multirow{3}{*}{ Geometry } & Tides & Yes & Yes & Yes & Yes & & \\
\hline & Band-pass & $10-30-380-500$ & $10-30-380-500$ & $5-10-350-380$ & $5-10-350-380$ & $30-50-300-350$ & $30-50-300-350$ \\
\hline & $\begin{array}{l}\text { Amplitude } \\
\text { correction }\end{array}$ & $\begin{array}{c}\text { Spherical } \\
\text { divergence }\end{array}$ & $\begin{array}{c}\text { Spherical } \\
\text { divergence }\end{array}$ & $\begin{array}{l}\text { Spherical } \\
\text { divergence }\end{array}$ & $\begin{array}{c}\text { Spherical } \\
\text { divergence }\end{array}$ & $\begin{array}{c}\text { Spherical } \\
\text { divergence }\end{array}$ & $\begin{array}{c}\text { Spherical } \\
\text { divergence }\end{array}$ \\
\hline \multirow{4}{*}{$\begin{array}{l}\text { 3D } \\
\text { Processing } \\
\text { workflow }\end{array}$} & NMO & $1477 \mathrm{~m} / \mathrm{s}$ & $1477 \mathrm{~m} / \mathrm{s}$ & $1500 \mathrm{~m} / \mathrm{s}$ & $1500 \mathrm{~m} / \mathrm{s}$ & $1500 \mathrm{~m} / \mathrm{s}$ & $1500 \mathrm{~m} / \mathrm{s}$ \\
\hline & Stacking & Yes & Yes & Yes & Yes & Yes & Yes \\
\hline & Interpolation & $6.25 \mathrm{~m}$ & $6.25 \mathrm{~m}$ & $6.25 \mathrm{~m}$ & $6.25 \mathrm{~m}$ & $6.25 \mathrm{~m}$ & $6.25 \mathrm{~m}$ \\
\hline & Migration & $\begin{array}{l}\text { 3D stolt, } \\
1500 \mathrm{~m} / \mathrm{s}\end{array}$ & $\begin{array}{l}\text { 3D stolt, } \\
1500 \mathrm{~m} / \mathrm{s}\end{array}$ & $\begin{array}{l}\text { 3D stolt, } \\
1500 \mathrm{~m} / \mathrm{s}\end{array}$ & $\begin{array}{l}\text { 3D stolt, } \\
1500 \mathrm{~m} / \mathrm{s}\end{array}$ & $\begin{array}{l}\text { 3D stolt, } \\
1500 \mathrm{~m} / \mathrm{s}\end{array}$ & $\begin{array}{l}\text { 3D stolt, } \\
1500 \mathrm{~m} / \mathrm{s}\end{array}$ \\
\hline
\end{tabular}


did not show any effect for either of the surveys and was therefore not applied.

After global adjustments (steps 1 and 2), the average TS between shallow and deeper intervals varied from 0.1 to $0.9 \mathrm{~ms}$. Similarly, small TS variations (1-2 ms on average) were observed between inlines due to residual static differences (assumed to mainly be associated with tide uncertainties). The trace-by-trace time corrections (step 3) resulted in a reduction of these residual TS in the shallower parts. Moreover, the final trace-by-trace time-variant shift process (step 5) efficiently improved the repeatability in the deeper intervals by reducing the remaining small depth consistent time differences (Figures 6, 8, and 9).

\section{Repeatability of P-cable data in a Fjord setting: Lyngen 2012-2014}

The 3D seismic data from the Lyngen area were analyzed in the time window $400-650 \mathrm{~ms}$. Here, the average $N \mathrm{rms}$ value decreased from 0.94 to 0.47 and the average predictability increased from 0.77

Table 2. The 4D preprocessing and processing workflows used in the study.

This study 4D preparation and processing flow

$\begin{array}{ll}\text { 3D seismic } & \text { Input of SEGD files } \\ \text { processing } & \text { Geometry assignment and filtering } \\ & \text { Removal of bad channels } \\ & \text { Tide corrections } \\ & \text { 3D Binning }(6.25 \times 6.25 \mathrm{~m}) \\ & \text { Spherical divergence correction } \\ & \text { Band-pass filter } \\ & \text { NMO using a velocity of } 1500 \mathrm{~m} / \mathrm{s} \\ & \text { Ensemble stacking } \\ & \text { Interpolation } \\ & \text { 3D Stolt migration }\end{array}$

4D preprocessing Cut seismic to overlap (SeisSpace).

Redefine geometry to common CDPs, inlines and crosslines (SeisSpace).

Bulk shift repeat to match reference using seafloor mean (Petrel).

Phase shift if repeat and reference are of reverse polarity compared with each other (Petrel).

Noise attenuation (GeoTeric).

Rescalingseismic amplitudes of repeat and reference to a common average using a mean rms of 500 (HRS Pro4D).

4D processing 1) Phase and time correction: global

2) Matching filter phase and amplitude using a shaping filter: global and combined)

3) Time correction (no phase): trace-by-trace

4) Rescaling amplitudes: global

5) Time variant TS correction: Precondition XC and TS. (HRS Pro4D)

4D interpretation Using seismic-difference cubes, modified repeat and reference seismic data.

Nrms, predictability, TS volumes, and slices.

Investigating anomalies in chimneys and along the BSR. to 0.81 at the end of the $4 \mathrm{D}$ processing flow (Figure 6 , steps $1-5$ ). Similarly, the phase and TS decreased from $9.4^{\circ}$ to $0.7^{\circ}$ and -0.7 to $01 \mathrm{~ms}$, respectively.

The Lyngen site consists of two main units:

Unit 1 (i.e., stratified sediments) has a final average $\mathrm{Nrms}$ value predictability and $N$ rms values of approximately 0.97 and 0.28 , spectively (Figure 6, step 5, subarea 1). The remaining 4D anomaies of unit 1 appear as (1) a striping imprint (Figure 6, step 5) due to overage gaps in 2014 and (2) a cluster of 4D anomalies in the outhern part above the peak of the moraine ridge (Figure 6, step 5).

Unit 2 has a more chaotic and undulating seismic facies caused by the moraine ridge and the moraine material below (Figure 2). The processing resulted in a final $\mathrm{Nrms}$ value of 0.73 (Figure 6 , 5 ), a crosscorrelation value of 0.73 (Figure 6, step 5), and an average TS difference of $0.004 \mathrm{~ms}$ (Figure 6, step 5). The repeatability decreases with depth within this unit (Figure 6, step 5).

We analyzed the repeatability of the Lyngen data using different frequency bandwidths (Figure 7a). Interestingly, the repeatability prior to 4D processing increased by decreasing the frequency bandwidth (i.e., 0.94 for a broad frequency band and 0.73 for a narrow frequency band). After processing, the $N$ rms value for units 1 and 2 using the broad frequency band was 0.35 and 0.79 , respectively (Figure $7 \mathrm{~b}$ ). The midcase scenario (where we reduce the frequency band around the dominant frequency) produced the lowest average $N$ rms of 0.23 (unit 1) and 0.70 (unit 2) (Figure 7b). The narrow case (cutting more high frequencies) did not result in a further increase of repeatability but resulted in an average $\mathrm{Nrms}$ to 0.30 for unit 1 (Figure $7 \mathrm{~b}$ ). A decrease in the $\mathrm{S} / \mathrm{N}$ when moving the frequency band below the dominant frequency might explain this phenomenon (Figure 7c).

\section{Repeatability of P-cable data in a formerly glaciated margin: Snøhvit 2011-2013}

During the 4D processing, the average $\mathrm{Nrms}$ and predictability (time window 440-740 ms TWT) improved from 0.62 to 0.36 and 0.83 to 0.89 , respectively (Figure 8, steps $1-5$ ). Similarly, the globally derived phase and TS are adjusted from $1.3^{\circ}$ to $-0.5^{\circ}$ and 0.5 to $-0.03 \mathrm{~ms}$, respectively. Moreover, the two depth intervals became comparable in 4D quality (Figure 8, step 5).

Between the baseline and the final processed monitor survey, the underlying dipping reflectors are close to perfectly matched, while some patches of 4D anomalies still exist especially along the seafloor and URU (Figure 8, step 5). Other remaining 4D anomalies are as comparable with the Lyngen data, weak inline-directed amplitude differences. To investigate if the random 4D anomalies were related to faults, plow marks (Osdal et al., 2010), or buried pockmarks, we 
calculated the variance of the Snøhvit 2011 seismic for intervals 1 and 2. Variance evaluates the continuity of seismic reflections, and it is an ideal attribute for identifying faults and fractures. Areas with very low coherence (marked as blackened areas in Figure 8, step 5) are draped on top of the predictability maps and indicate the occurrence of faults. These low-variance areas coincide with the 4D anomalies (low-predictability areas). Along the seafloor, the location of pockmarks (Figure 3) coincides with the 4D anomalies (Figure 8, step 5) and subsurface faults.

\section{Repeatability of P-cable data in a deepwater Arctic basin: Vestnesa 2012-2013}

The preprocessed seismic difference between Vestnesa 2013 and 2012 in time window $1640-1840 \mathrm{~ms}$ shows preprocessed $\mathrm{Nrms}$ and predictability values of 0.71 and 0.77 , respectively (Figure 9, initial). Here, inline-striping imprints caused prominent TS anomalies between the data sets, and we observed significant 4D amplitude anomalies at chimney locations. The overall 4D process improved the average $N \mathrm{rms}$ and predictability to 0.38 and 0.86 , respectively (Figure 9, initial to 5). The final 4D anomalies between Vestnesa 2012 and 2013 are mostly concentrated in seismic chimneys and along the faults where 4D changes caused by fluid flow are expected (Figure 9). The best seismic repeatability was found in the strata outside the chimneys, presenting an average $\mathrm{Nrms}$ and predictability of 0.3 and 0.95 , respectively (step 5, Figure 9).

\section{DISCUSSION}

\section{D noise connected to P-cable acquisition}

The main acquisition-related factors influencing the $\mathrm{S} / \mathrm{N}$ and reproducibility of marine-towed seismic data typically relate to the acquisition system and execution of the survey, such as survey geometry and operating parameters, or they relate to environmental effects (Calvert, 2005).

\section{Acquisition system and execution of the surveys}

On the final Lyngen difference data, slightly poorer repeatability relates to some data-coverage gaps (Figure 9, step 5). Besides that, we do not identify any significant differences that relate to the survey geometry or execution at any of the sites. A reasonable reproducibility of the survey geometry, source signal, and noise level is thus manifested in the similarity in the amplitude spectra (Figures 2-4) between the baseline and monitor surveys at all locations. By using the same vessel to acquire the different surveys, the ship-noise effect on repeatability was also minimized. The compactness of typical high-resolution seismic systems led to less drift and feathering than conventional towed marine streamers. The typical dense grid of the data reduces positioning errors by decreasing the lateral positioning shifts between the baseline and monitor survey to a couple of meters (within the bin size of the surveys).

\section{Weather and water effects}

Environmental effects are typically associated with weather and water effects (Calvert, 2005). To minimize weather effects, we collected all data sets at the same time of the year and in similar wave conditions $<2 \mathrm{~m}$. Moreover, the different time-lapse data sets were processed using identical water velocity and were tide corrected. However, the average water velocity or water column height probably differed somewhat from year to year causing the minor global TS differences (1-2 ms) between the surveys (Table 4). As an example, the average TS difference of $1 \mathrm{~ms}$ at the seafloor of the Vestnesa 4D data sets corresponded to a small, approximately $1 \mathrm{~m} / \mathrm{s}$ average velocity change between the surveys. Furthermore, the Lyngen and Snøhvit data sets as well as Vestnesa 2013 have significant noise in the inline direction manifested in small inline tide-periodical shifts. In contrast, Vestnesa 2013 was smooth, without visible inline striping trends.

The slight changes in water column height or velocity might be related to changes in temperature, salinity, or local water column height differences. The weather was worse during the acquisition of Lyngen 2012, Snøhvit 2013, and Vestnesa 2012 compared with their time-lapse pair indicated by an approximately $4-10 \mathrm{~m} / \mathrm{s}$ increase in average wind speed (Table 4). This effect is possibly evident in Lyngen 2012 and Snøhvit 2013 as low-frequency noise and in Lyngen 2012 and Vestnesa 2012 as stronger static variations (compared with Lyngen 2014 and Vestnesa 2013, respectively) (Figures 2 and 4 ) due to the rougher sea, swells, or more frequent changes in water properties. The weather effect is also evident from the $\mathrm{S} / \mathrm{N}$ between the surveys; i.e., the Vestnesa data havea lower $\mathrm{S} / \mathrm{N}$ in 2012 (12.9) compared with in 2013 (18.9). Conversely, the Lyngen 2014 and Snøhvit 2011 are acquired in better weather yet show lower $\mathrm{S} / \mathrm{N}$ compared with their time-lapse match. A more moderate $\mathrm{S} / \mathrm{N}$ can alternatively be explained by other dominant

Table 3. The 4D processing methods and their main applications.

Method

What it does
Applies a global or average bulk and phase shift of the monitor survey to better vertically align the time and phase to the base.

A global frequency bandwidth and phase-shaping filter applied to the monitor survey to match those with the base.

using a shaping filter

Trace-by-trace time and phase correction

Rescaling amplitudes

Time variant TS correction
Correct for misalignments in time (and phase if chosen) between monitor and base surveys because of shallow static differences (e.g., differences in sea level).

Normalizes the amplitudes if not in balance (if rms factor is not close to one) using a new scalar from the base survey.

Compensates and corrects for differences in traveltime of reflection events, caused by a stretch in the data and velocity changes due to nearby fluid/gas areas. 
et al., 2017), we did not expect it to have any visible effect, which our analysis confirmed. That is, we could not identify any differences in residual TS in areas of active- or inactive seep sites. Overall, the final TS (after tide corrections, bulk shift, statics, and the time-variant shift using $1 \mathrm{~ms}$ threshold) along the seafloor are as low as -0.2 to $0.2 \mathrm{~ms}$ here, which is to the sample rate $(0.25 \mathrm{~ms})$

\section{Trace fold and repeatability}

A higher trace fold normally leads to a betterS/N. Andorsen and Landro (2000) show that the rms difference between time-lapse data decreases linearly from approximately $16 \%$ to $3 \%-4 \%$ between unstacked and 50 trace-fold data. Snøhvit 2011 data have a trace fold of 7 and $\mathrm{S} / \mathrm{N}$ of 31.5, whereas Snøhvit 2013 data have a trace fold of
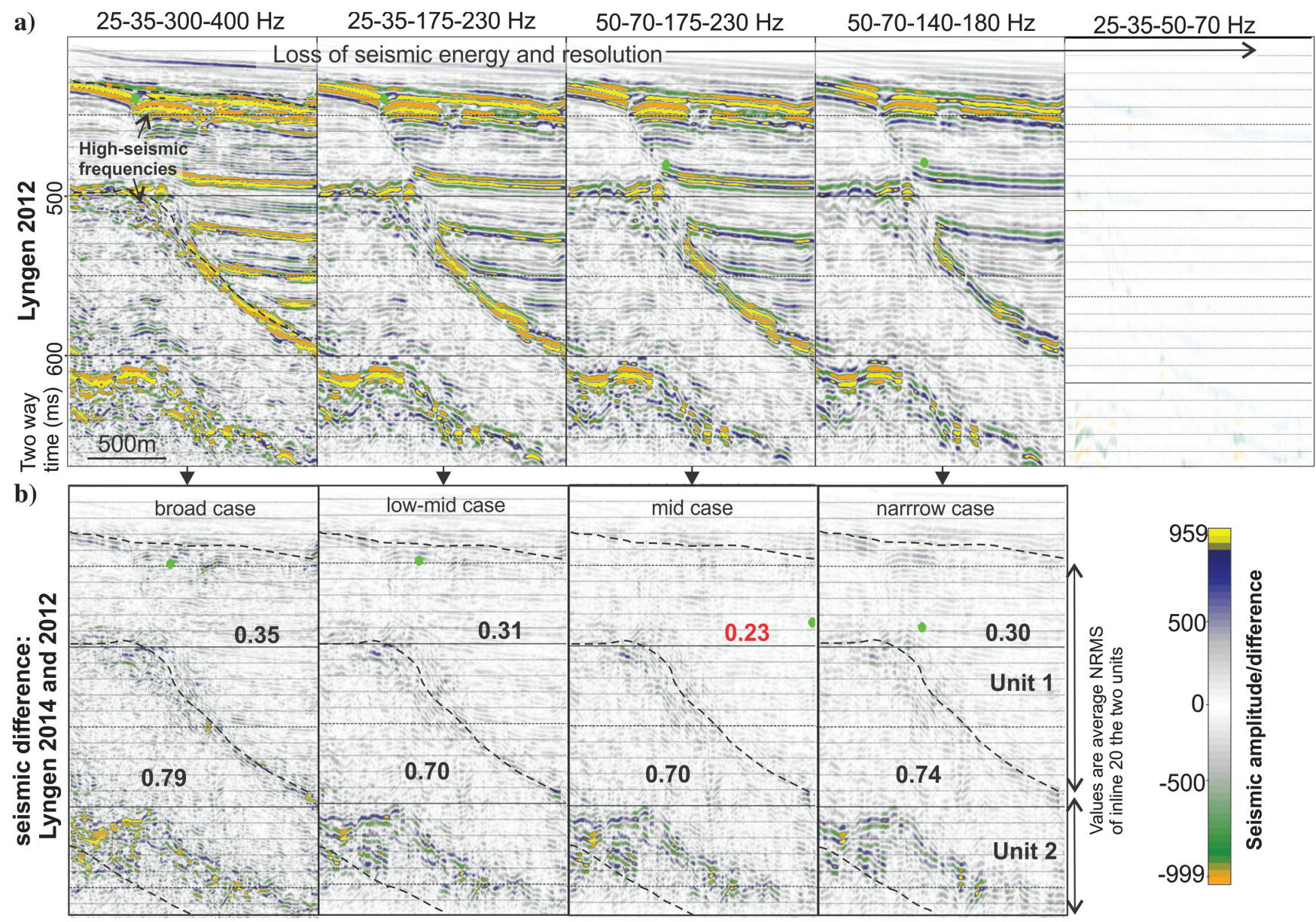

c)

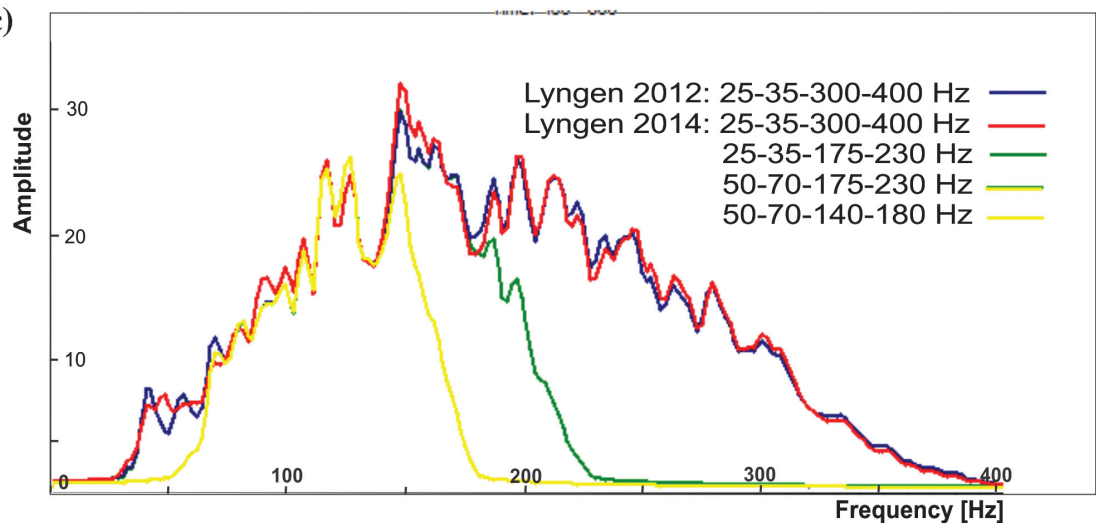

Figure 7. (a) Seismic example of Lyngen 2012 filtered with different band-pass filters (inline 20, the area is shown in Figure 6), and (b) corresponding final seismic difference example and $\mathrm{Nrms}$ values of units 1 and 2. (c) Amplitude spectrum of the different band-pass-filtered Lyngen 214 and Lyngen 2012 as a reference for comparison. The best repeatability values are achieved with a narrow band-pass filter centered on the dominant frequency $(50-70-175-230 \mathrm{~Hz})$. 
Initial - scaled
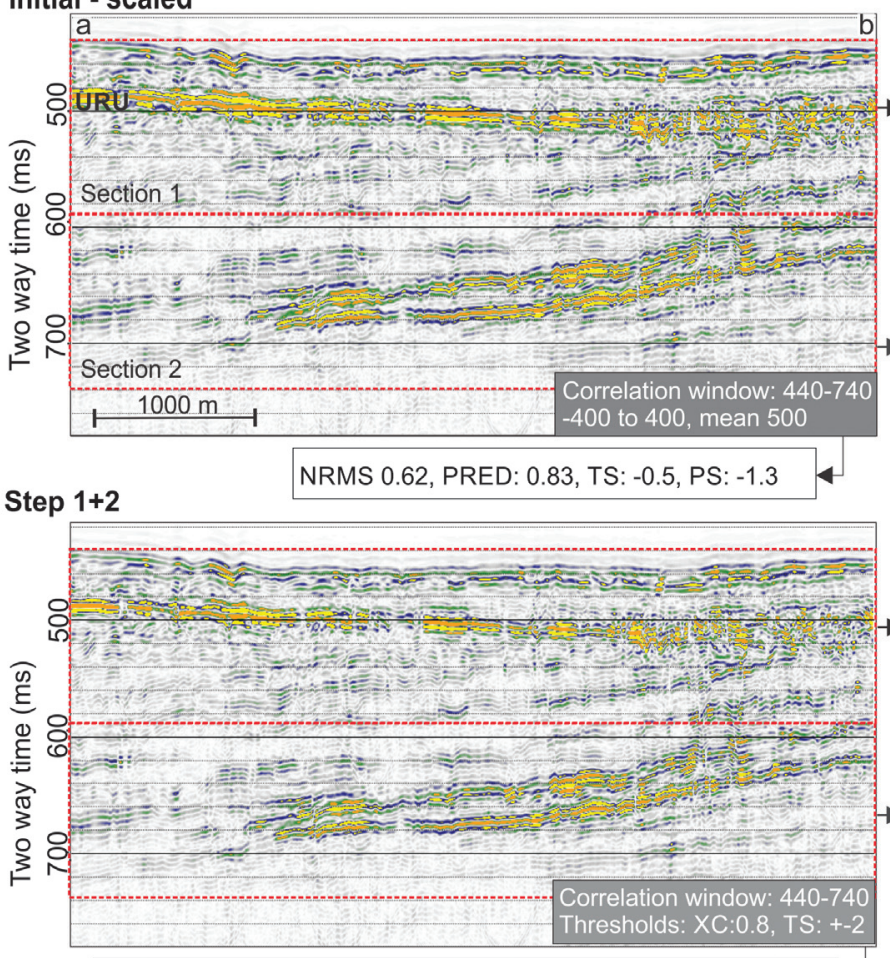

Step 3 NRMS 0.55, PRED: 0.84, TS: -0.4, PS: 1.1(step 1), $0.15($ step 2$)$
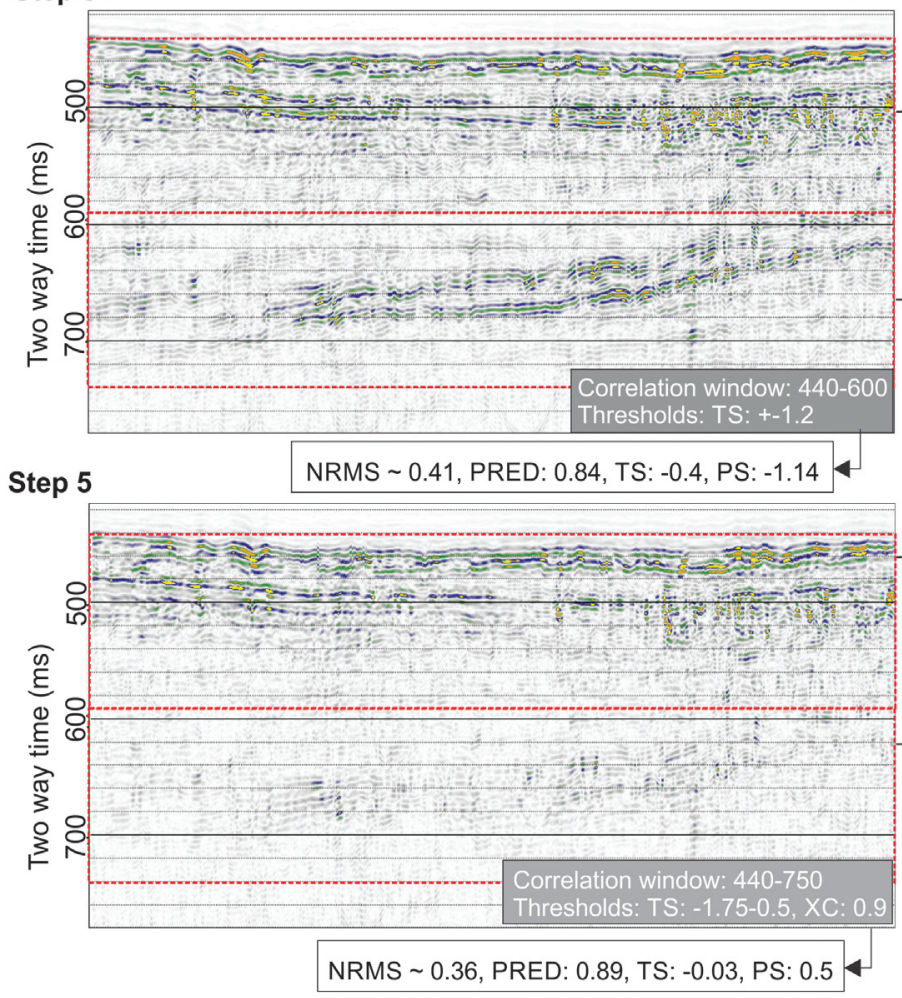

$-875$

$440-590 \mathrm{~ms}$

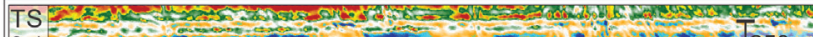

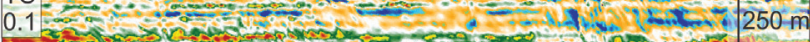
a PRED FP 0.82 NRMS

0.56

$590-740 \mathrm{~ms}$

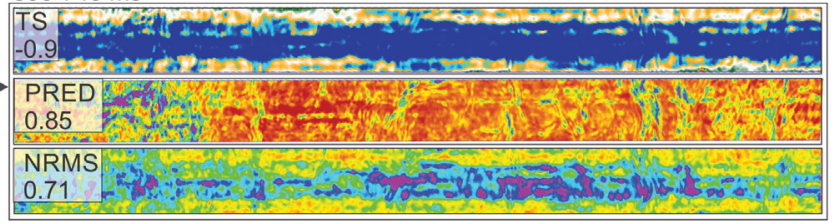

NRMS

$440-590 \mathrm{~ms}$

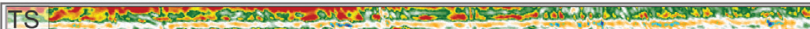

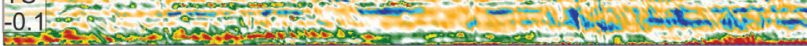

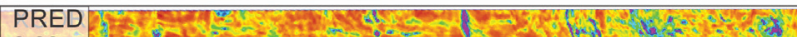

0.83

NRMS

0.54 . on

$590-740 \mathrm{~ms}$

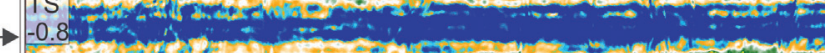

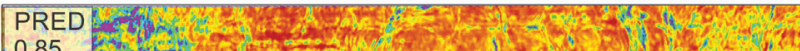

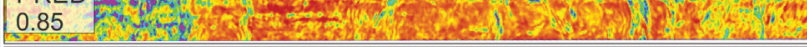

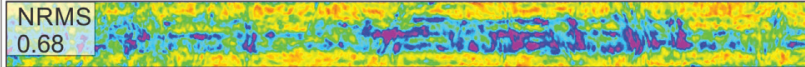
$440-590 \mathrm{~ms}$

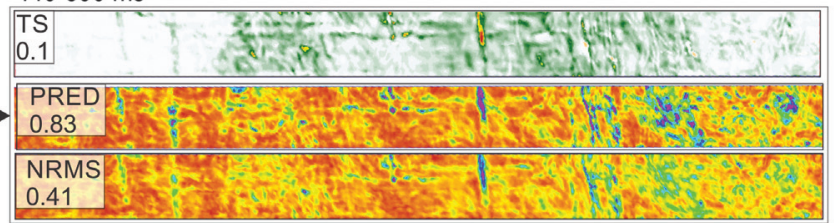

$590-740 \mathrm{~ms}$

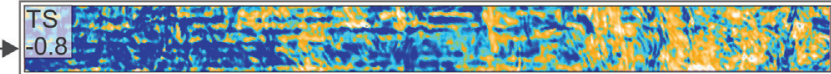
\begin{tabular}{lll}
\hline PRED GP \\
085
\end{tabular} $0.85 \mathrm{R}+\mathrm{H}$. NRMS 0.60

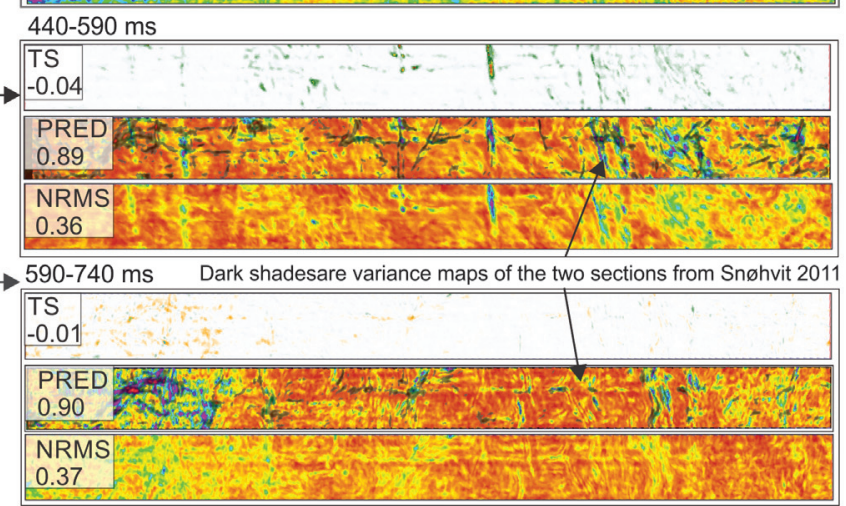
$\begin{array}{llllllllll}-375 & 0 & 411 & 839 & 1.2 & 0.7 & 0.3 & 0 & 0.3 & -0.7\end{array}$ $-1.21 .0$ $0.9 \quad 0.8 \quad 0.7 \quad 0.6$ \begin{tabular}{rrrrr}
0.1 & 0.3 & 0.6 & 0.9 & 1.1 \\
\hline & NRMS &
\end{tabular}

Figure 8. The 4D processing flow of Snøhvit 2013-2011 with processing parameters. The left column shows seismic difference after various processing steps and average repeatability measures of the window between 440 and $740 \mathrm{~ms}$ TWT. The right column shows corresponding TS, predictability, and NRMS maps of interval $1(440-590 \mathrm{~ms})$ and interval $2(590-740 \mathrm{~ms}$ TWT). Step 5 predictability maps are draped with a coherence map of Snøhvit 2011 of the two intervals to indicate the poorer repeatability due to lack of continuity in the reflections. 

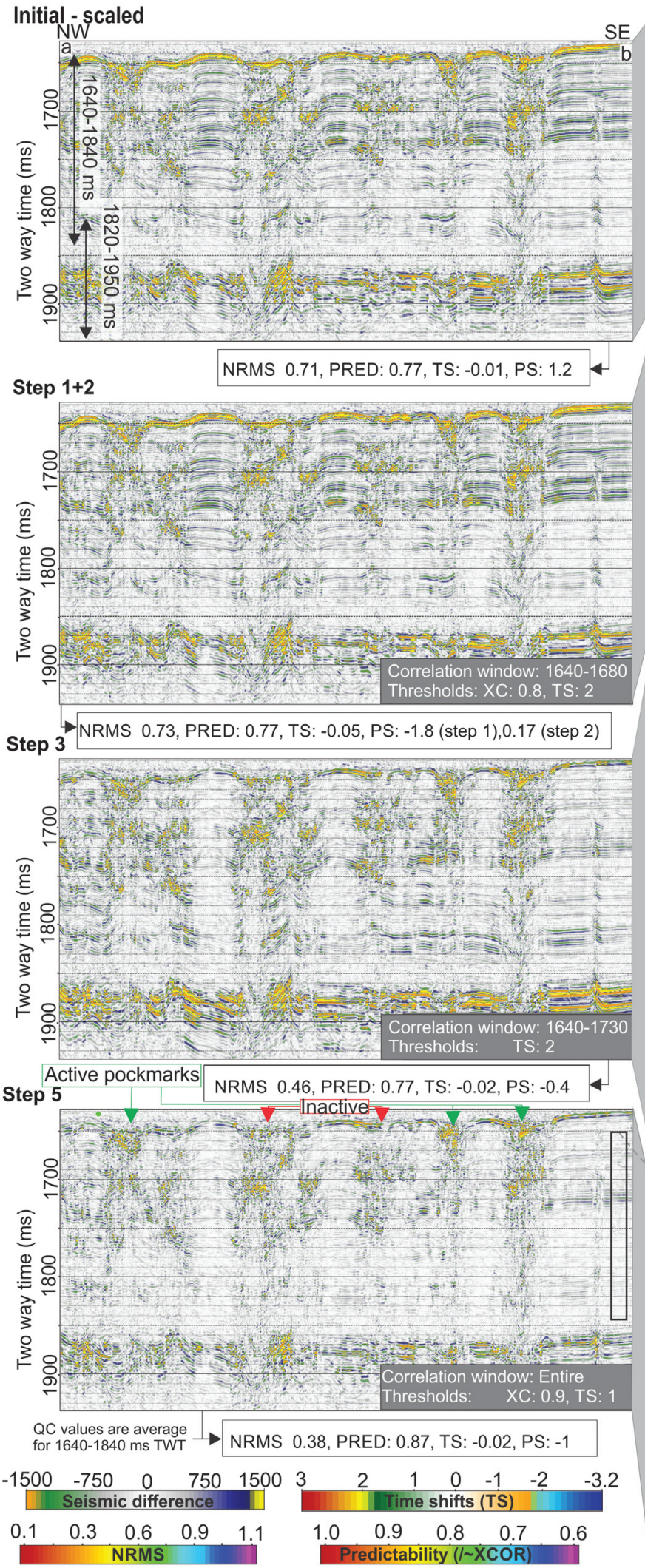

1640-1840 ms:
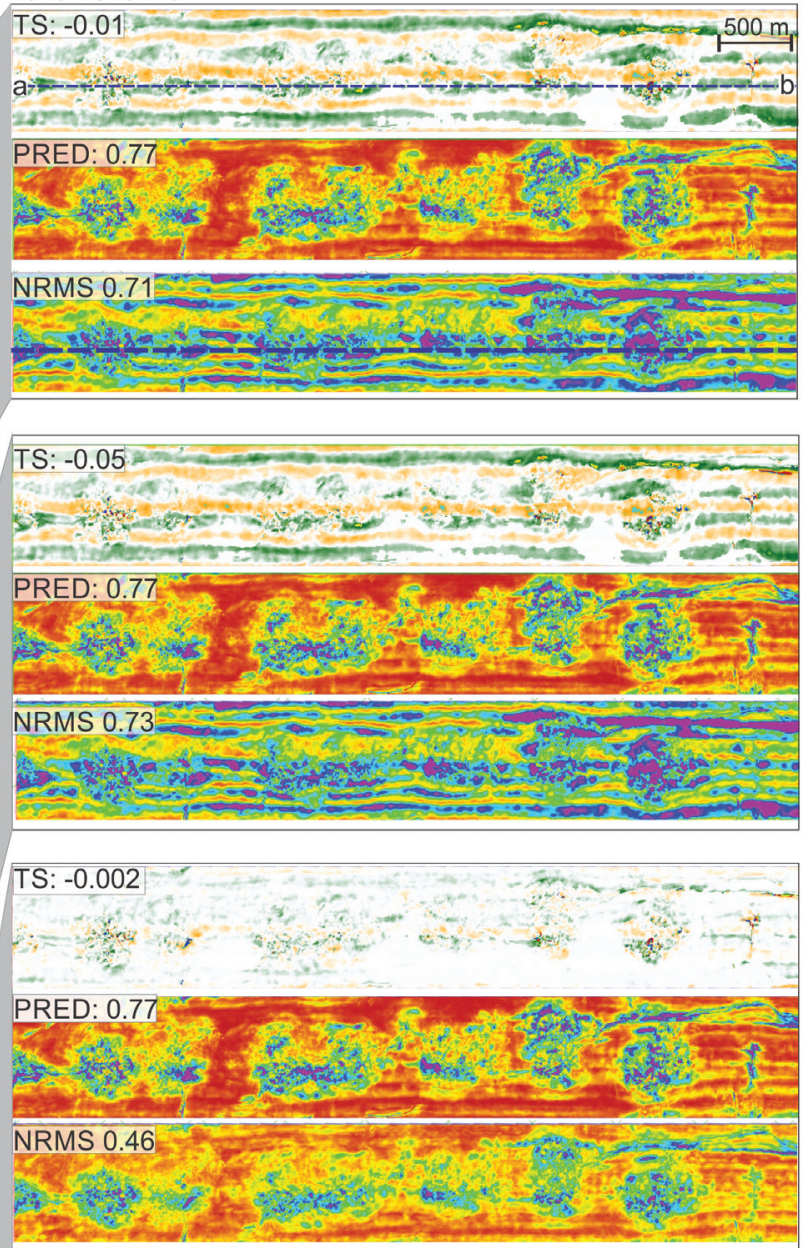

1820-1950 ms: Static time-shift (-2 to $2 \mathrm{~ms})$ still apparent around BSR

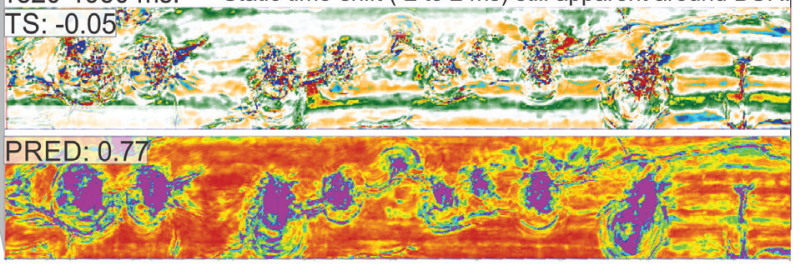

1640-1840 ms:

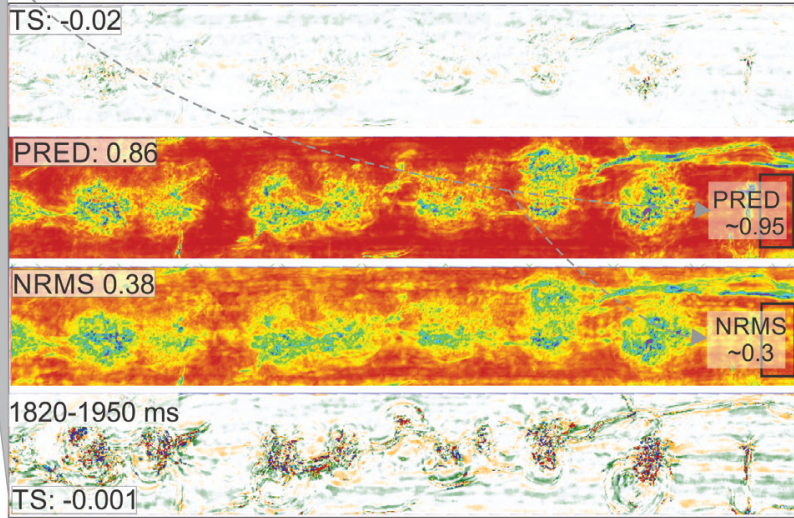

Figure 9. Seismic difference and repeatability measures between Vestnesa 2013 and Vestnesa 2012 during 4D processing. Seismic difference example (location in uppermost TS map) and TS, Predictability and Nrms map between the time window 1640-1850 ms two-way time after each 4D processing step. Values are average repeatability measures of the volumes. In addition, steps 3 and 5 include the TS map, and average values are presented between 1820 and $1950 \mathrm{~ms}$ TWT. 
11.5 and an $\mathrm{S} / \mathrm{N}$ of 43 , which might be explained by a comparable relationship between the trace fold and the noise level.

The Vestnesa 4D data sets are possibly affected by the difference in the shooting rate (Table 1), due to the combined effect on the trace fold and residual shot noise. The different shot rates $(4 \mathrm{~s}$, Vestnesa 2012; 5-6 s, Vestnesa 2013) likely cause the variation in average trace fold, which is 7.2 for Vestnesa 2013 compared with 8.7 for Vestnesa 2012. To investigate the isolated effect of average trace fold and total S/N, we rebinned the Vestnesa 2013 data to half the bin size (3.125) and compared the two identical volumes of different bin sizes. We found that the larger shot interval that reduced the trace-fold of the Vestnesa 2012 survey may have contributed to an approximately $20 \%$ reduction in ambient noise (related to lower trace-fold), but only an approximately $10 \%$ reduction in overall noise that is considered to be a combination of ambient noise and residual shot noise (see Appendix B for calculations). However, it is not a direct positive relationship between the trace fold and the increased S/N because Vestnesa 2012 has an S/N of 12.9 and Vestnesa 2013 has an $\mathrm{S} / \mathrm{N}$ of 18.9.Thus, other noise effects between the data sets must explain the difference in noise level.

\section{Residual shot noise}

Energy arriving at the receivers from previous shots may introduce an additional source of noise affecting the data repeatability. A larger time interval between firing shots not only reduces the average trace fold, but it can contribute positively to less noise interference from previous shots. The nonrepeatable nature of the residual shot noise can typically cause poorer repeatability of time-lapse data (Landrø, 2008).

Table 4. Summary of parameters that influence repeatability of the data.

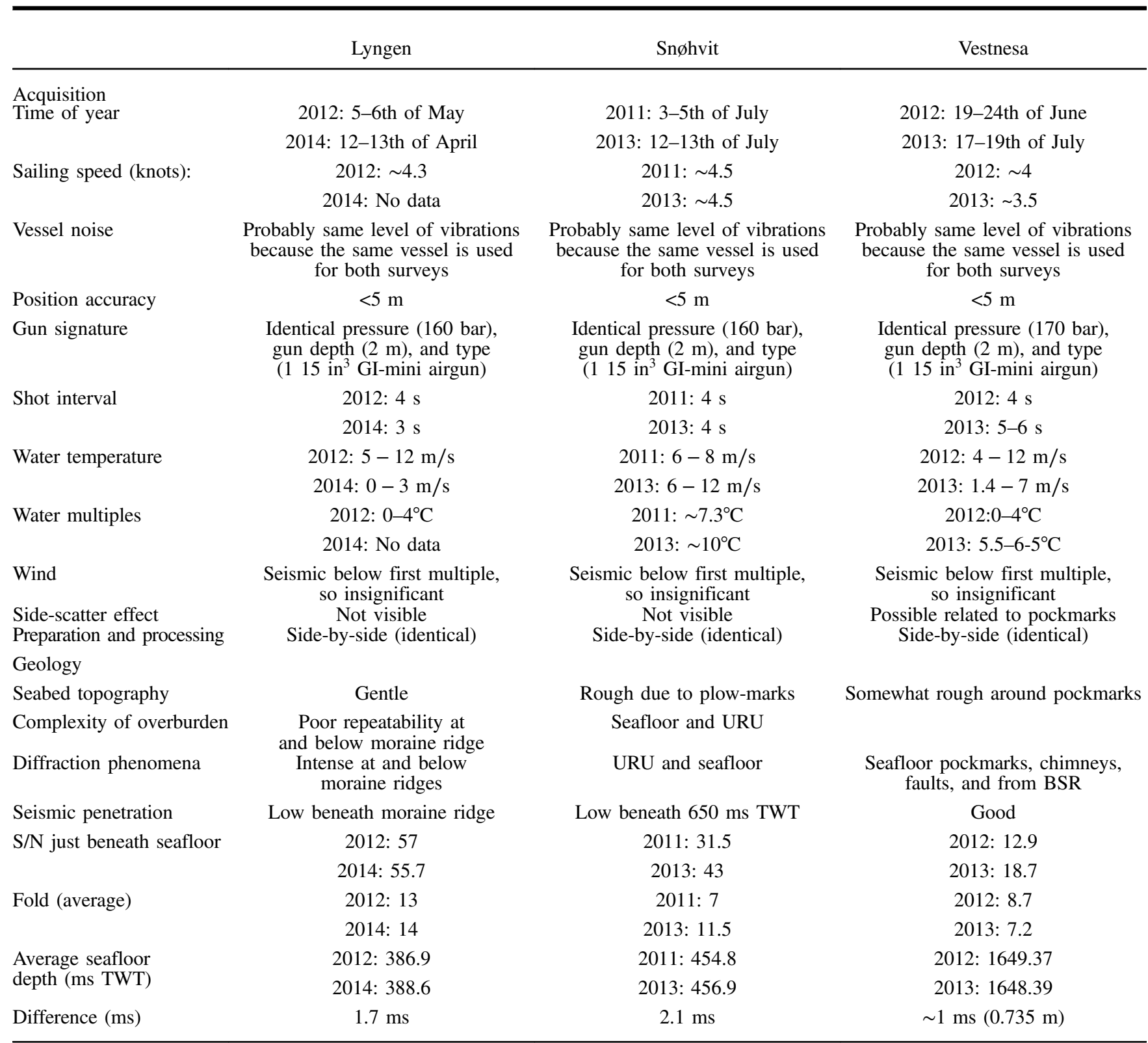


Due to the relatively shallow water in the Lyngen area, we found that the seafloor reflection multiples bounce approximately seven times between two shots at a shot rate of $3 \mathrm{~s} \mathrm{(3/0.4} \mathrm{s} \mathrm{TWT} \mathrm{to} \mathrm{sea-}$ floor). Every time this occurs, more energy will be attenuated. Consequently, the sound energy from the previous shot is greatly attenuated; hence, it is therefore likely insignificant whether fired at 3 or $4 \mathrm{~s}$.

The Vestnesa data have on the contrary approximately four times greater water depth than the Snøhvit and Lyngen data (Table 4, equation B-1) and will thus be more affected by residual shot noise. Compared to Vestnesa 2013, more residual shot noise is expected in Vestnesa 2012 because the survey is acquired with a shorter shot interval. Inspecting the reflective energy difference in the water-column confirms this assumption (Figure 10).

Landrø (2008) investigates the effect of shot-generated noise by analyzing and modeling amplitude decay versus recording time for conventional marine streamers. Using their proposed equation from that study (see Appendix B), we find that the reduction in the shot interval between the Vestnesa 2012 and 2013 surveys can cause a decrease in residual shot noise by approximately $77 \%$; however, consequently there is an increase in ambient noise by approximately $20 \%$ due to less average fold. The residual shot noise is indicated to represent approximately53\% of the total noise in the Vestnesa 2012 survey (and 16\% of the total in Vestnesa 2013). Assuming that this is true, the remaining ambient noise difference is likely related to weather and wave effects and is calculated to cause approximately a $38 \%$ difference in noise level between the surveys. We conclude that the difference in $\mathrm{S} / \mathrm{N}$ between the surveys is likely a combination of residual shot noise, weather and water-effects, and trace fold.

\section{Noise in the Snфhvit data}

There is, however, an overall noticeable difference between the three sites that does not seem to be explained by weather, fold, or residual shot noise. That is the apparent higher level of 3D and 4D noise in the Snøhvit data relative to the two other sites and the significant difference in the $\mathrm{S} / \mathrm{N}$ between the Snøhvit surveys (31 in 2013 versus 43 in 2011). We speculate whether some of this noise is related to production at the Snøhvit field. The survey, in fact, covers the main hub at the seafloor (Hansen et al., 2011).

The high frequencies emitted by the source are quickly reflected at the Snøhvit site due to a relative hard seafloor and higher velocity strata, reflected in a low dominant frequency. Lack of high frequencies might, therefore, justify the action of applying a relatively narrow frequency filter compared with the other surveys to reduce $3 \mathrm{D}$ and 4D noise here.

\section{Processing effects on P-cable repeatability}

The preprocessing steps significantly increased the repeatability (Table 2). Remaining time-related static differences and seismic veloc- ity changes were further adjusted for during the local TS correction routines. In particular, the $4 \mathrm{D}$ processing routine of all case studies showed that the second trace-by-trace time correction was necessary for improving repeatability by correcting for smaller residual static changes. Applying prestack residual static corrections based on a time average calculated along the seafloor could lead to a better

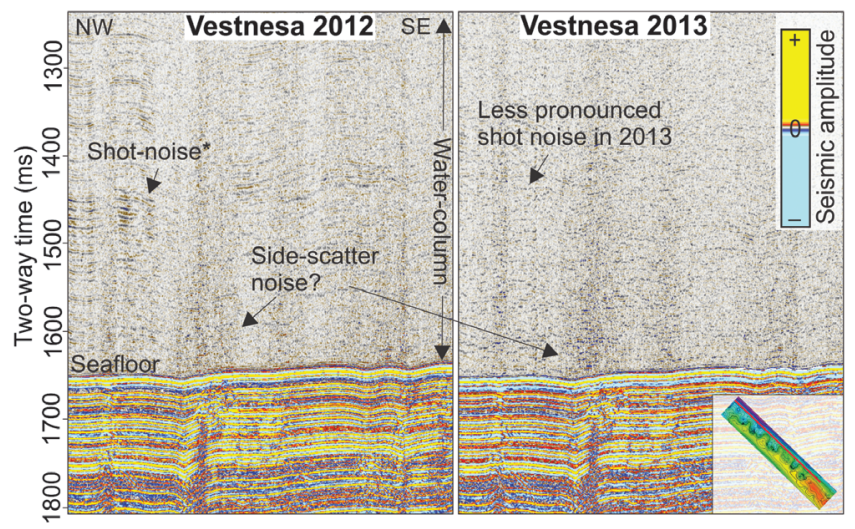

Figure 10. Reflective energy/noise in the water column at Vestnesa 2012 and 2013 as shot noise (multiple energy from the previous shot) and potentially side-scatter effect due to the seafloor topography.

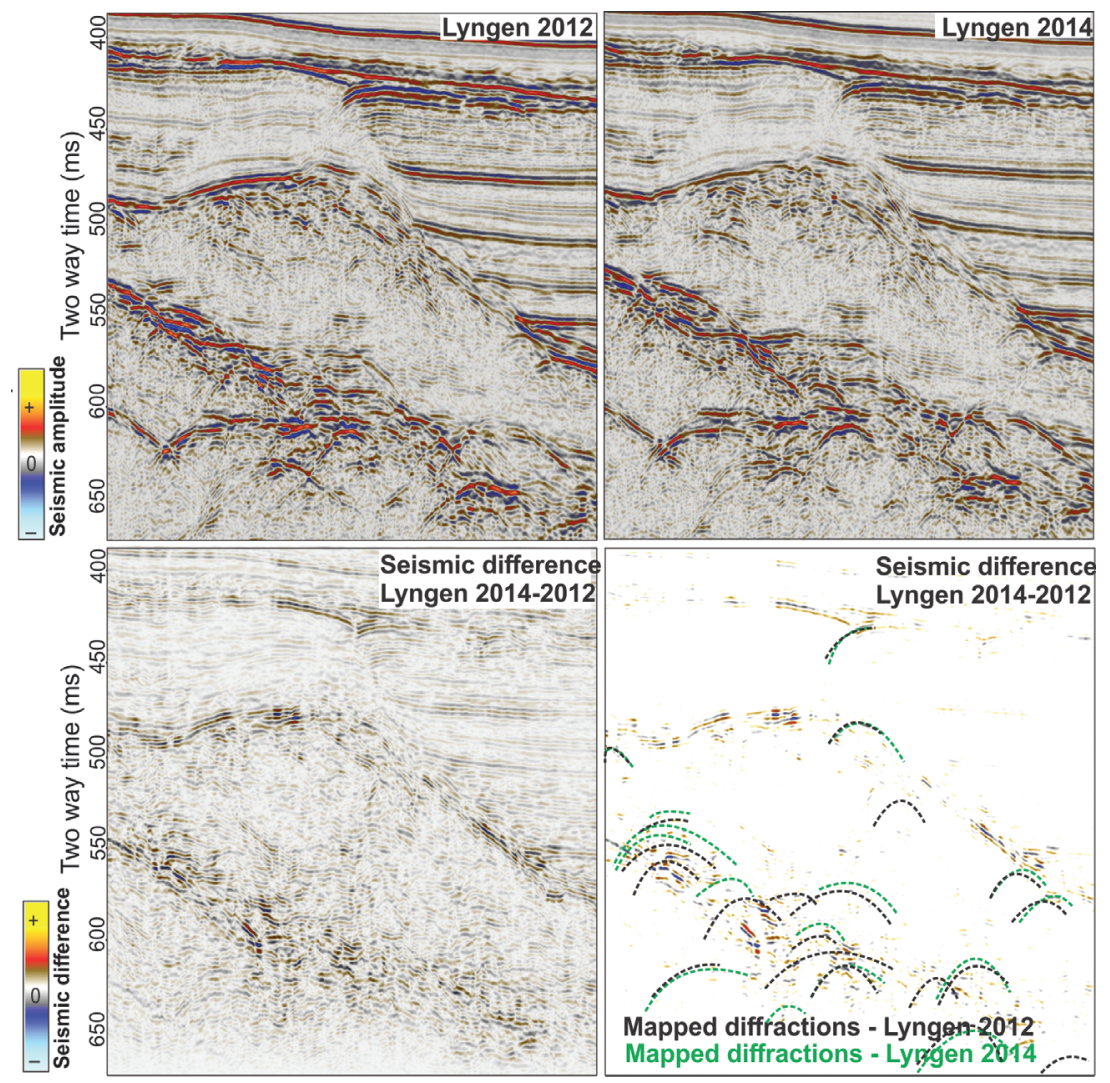

Figure 11. Stacked inline (unmigrated) of Lyngen 2012 and 2014 and seismic difference of migrated Lyngen 2014-2012. In the lower right corner, diffractions drawn from the two seismic inlines drapes the difference anomalies that are enhanced by illumination. 
final repeatability. However, this processing step could compromise the resolution of the data by smoothing the shape and depth of a small pockmark or plow marks.

Match of phase and amplitude as well as rescaling the amplitudes in step 4 provided negligible improvements.

\section{Geology-related time-lapse seismic differences}

From the three investigated sites, we achieved a good sense of the effect that major geologic structures have on the repeatability of the time-lapse data. We particularly observed lower repeatability associated with harder or more undulating morphology, such as the moraine ridges in Lyngen and along the URU in the Snøhvit area (Table 4). Slight deviations in the source-receiver positions and orientations across complex surfaces cause differences in seismic scattering signals (Misaghi et al., 2007). In turn, this probably led to some discrepancies in the collapse of diffraction hyperbolic events during migration and distortion of traces in the form of small TS or amplitude variations beneath (Malme et al., 2005; Osdal et al., 2010). The seismic response from the lowermost moraine ridge in the Lyngen area is dominated by diffractions (Figure 11). However, there are places where no 4D anomalies are observed indicating that the primary reflections are undisturbed (Figures 2-4). Only (monitor) amplitudes of $80 \%-100 \%$ similarity to the reference within a sliding time interval of $1 \mathrm{~ms}$ were adjusted during the last time-variant 4D processing step. This implies that we are able to repeat most amplitude reflections along the unconformities and undulating surfaces using rather strict thresholds (e.g., Figure 11).

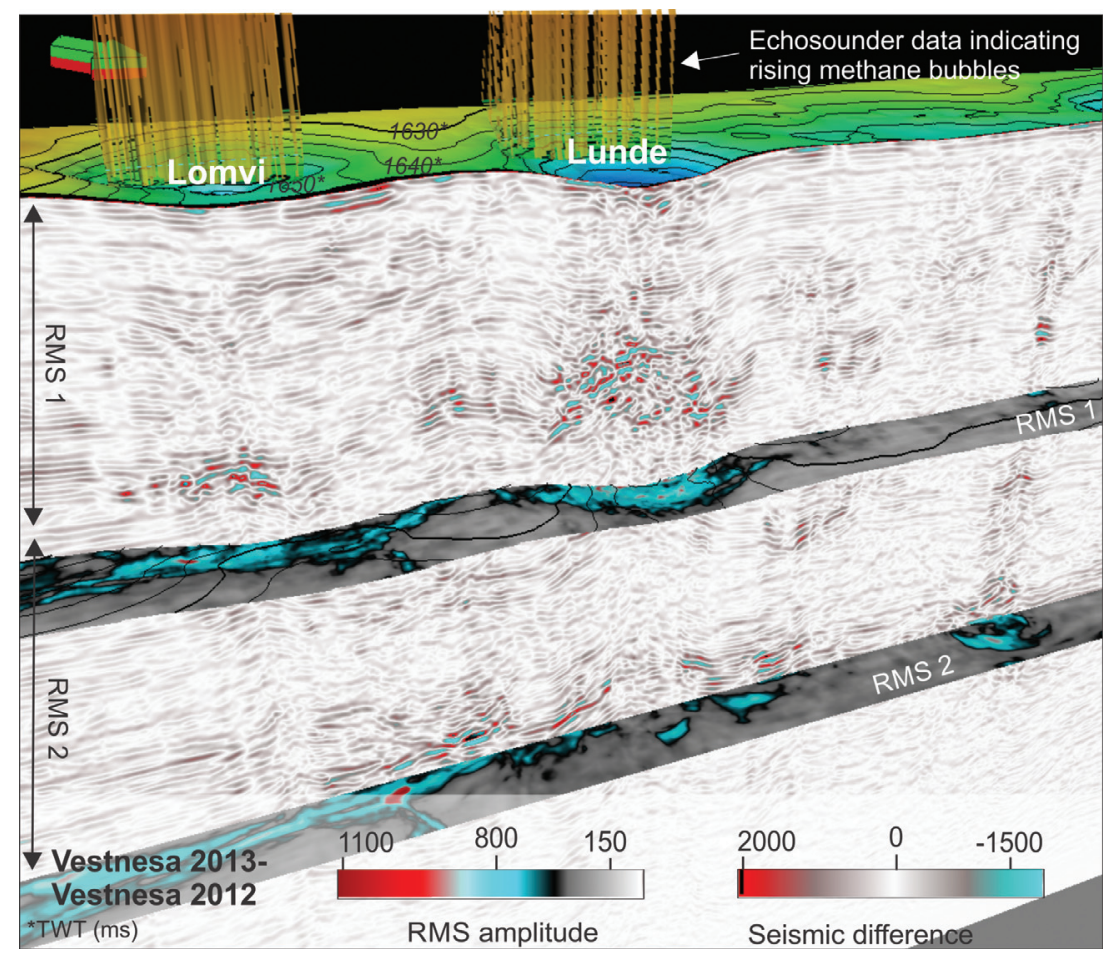

Figure 12. Final seismic difference between Vestnesa 2012 and 2013 (location presented in Figure 4) in the Lunde-Lomvi area and echosounder data showing the location of methane bubbles in the water column. The rms amplitude anomaly map at two intervals (rms 1 and 2) shows how the 4D anomalies appear laterally.
The subsurface fluid-flow system of the Vestnesa ridge is incised in soft marine sediments where we obtained an average $\mathrm{Nrms}$ value of $30 \%$ and predictability of $95 \%$ (Figure 8 ). Within gas chimneys, the repeatability is lower and the validity of $4 \mathrm{D}$ anomalies is less reliable. Scattered energy and distortion of signals can, as mentioned, lead to locally poorer repeatability. In contrast to anthropogenic-controlled production of reservoirs, it is more challenging to predict or model subsurface changes at natural seep sites. However, we expect more 4D anomalies associated with pore-fill changes (saturation or pressure changes) underneath the actively leaking pockmarks (Figure 12). In the shallow subsurface (0-50 ms) of the active pockmarks, we do observe a higher abundance of 4D anomalies compared with just underneath the inactive pockmarks (Figure 12). We hypothesize that at least parts of this intensification of 4D anomalies (i.e., within chimneys and in the shallow subsurface of active pockmarks) are an effect of active fluid flow through the chimneys (Figure 9, step 5).

As a control on the 4D anomalies, we tested the repeatability of small structures within and outside of the chimney area. By comparing (manual) interpretation of small-scale faults on Vestnesa 2012 and 2013, we show that complex chimney structures in marine contourite deposits can be repeated, at least locally (Figure 13). The figure also shows that 4D anomalies occur in intervals along the chimneys restricted to areas around fractures and faults, especially at their termination. Such observations suggest that time-lapse investigations of these chimney features are potentially suitable for constraining fluid migration through faults and fractures.

\section{Repeatability of P-cable data compared with conventional seismic}

The highest repeatability values were achieved for the undisturbed well-stratified region on the Vestnesa Ridge (i.e., an average $\mathrm{Nrms}$ of $30 \%$ ). The stratified unit at the Lyngen region (i.e., unit 1) has average $N$ rms values that range from $28 \%$ to $39 \%$. The lower unit characterized by chaotic facies shows poor repeatability (i.e., average Nrms of $73 \%$ ). Repeatability of the Snøvit data sets is comparable to that of the Lyngen data (i.e., $36 \%$ ).

Among low (to mid)-frequency bandwidth data (the common bandwidth of industrial time-lapse data), the average $\mathrm{Nrms}$ achieved for marine-streamer 4D seismic data today is $20 \%-$ 30\% (Landrø and Amundsen, 2018). Landrø and Amundsen (2018) state that achieving an Nrms of less than $20 \%$ between repeats of marinestreamer data would largely depend on excellent weather, wave, and water-column conditions.

The $N$ rms generally increases with higher frequency content for the same amount of time or positioning shifts (4D noise) (Landrø et al., 1999; Kragh and Christie, 2002; Eiken, 2005; Lecerf et al., 2015). As an example, Lecerf et al. (2015) calculate an Nrms value of 18.6 and 27.4 for fixed small TS at 38 and $53 \mathrm{~Hz}$, respectively. That is a $10 \%$ decrease in $\mathrm{Nrms}$ for the same TS by only decreasing the frequency by $20 \mathrm{~Hz}$. In a repeatability study of $50-150 \mathrm{~Hz}$ vertical seismic 
profile (VSP) data, Pevzner et al. (2011) show prestack Nrms of $20 \%-30 \%$ of the $\mathrm{CO}_{2} \mathrm{CRC}$ Otway Project Case Study. In another study using a narrow, low-frequency bandwidth of 5-40 Hz, Anderson and Landrø (2000) show examples of zero-offset VSP data (10fold stack) with a very low Nrms error, $2 \%-4 \%$. Hatchell et al. (2017) test the repeatability of the HR3D P-cable data by comparing a line from a $3 \mathrm{D}$ survey with a $2 \mathrm{D}$ repeat. In a similar geologic setting as the stratified unit of Lyngen, they achieved an $\mathrm{Nrms}$ as low as $15 \%$.

In this study, we achieved comparable Nrms measures between the lower frequency and noisier Snøhvit data and the higher frequency and cleaner Lyngen data. Disregarding the frequency content, time-lapse data with varying residual noise levels might appear of similar 4D quality. Narrowing the bandwidth around the dominant frequency (Lyngen, mid-low case; Nrms 23\%), where the S/N should be at highest, might be an effective way to indicate a typical top-end repeatability (approximately 23\%) and assess the amount of nonrepeatable sources. Considering this, the main difference in comparison with our results (approximately 30\%-40\%) and Hatchell et al. (2017) Nrms measures (15\%) is that they use $100 \mathrm{~m}$ long streamers, use a 10 times larger source, and repeat the line in the same period. Repeating the line within just a couple of hours to days as well as the long streamers and source should be ideal for testing the lower end of the $\mathrm{Nrms}$ for that type of acquisition setup and frequency range. All these effects in addition to a higher average fold are beneficial for producing higher repeatability, which likely clarifies why the Hatchell et al. (2017) Nrms results are better.

Considering a higher dominant frequency and finer resolution than typical historical time-lapse data, we expected somewhat higher $N$ rms measures than the average $N$ rms for conventional $4 \mathrm{D}$ data today. It is worth stressing that the seismic resolution presented here is approximately four times higher than conventional broadband 3D seismic data. Depending on the target, however, if a somewhat lower resolution were acceptable, one would also increase the repeatability somewhat by increasing the CMP bin size and therefore the trace fold because this will enhance the $S / N$, leading to fewer residual differences. A higher $\mathrm{S} / \mathrm{N}$ can also be obtained without compromising the resolution by acquiring data with shorter sail-line spacing. Conversely, a lower percentage of data overlap should lead to a lower $\mathrm{S} / \mathrm{N}$ and thus poorer repeatability. This effect is illustrated by Landrø (1999), who shows how the rms difference increases with the shot separation. Nevertheless, we conclude that a repeatability of $30 \%-40 \%$ is acceptable, which should be promising for future 4D high-resolution investigations.

We suggest a few acquisition- and processing-related factors worth considering prior to potential future comparable time-lapse studies, such as implementing a wave gauge to measure water level, 4D binning, and calculations to more accurate streamer positioning (for more details, see Appendix C).

\section{CONCLUSION}

High-resolution 3D seismic data sets provide a detailed and accurate image of the shallow subsurface typically down to 500 $1000 \mathrm{~m}$ below the seafloor. We propose a processing workflow and demonstrate that the small-offset, high-resolution P-cable 3D seismic system (approximately $30-350 \mathrm{~Hz}$ ) can be used as a time-lapse tool resolving changes in acoustic impedance on a meter

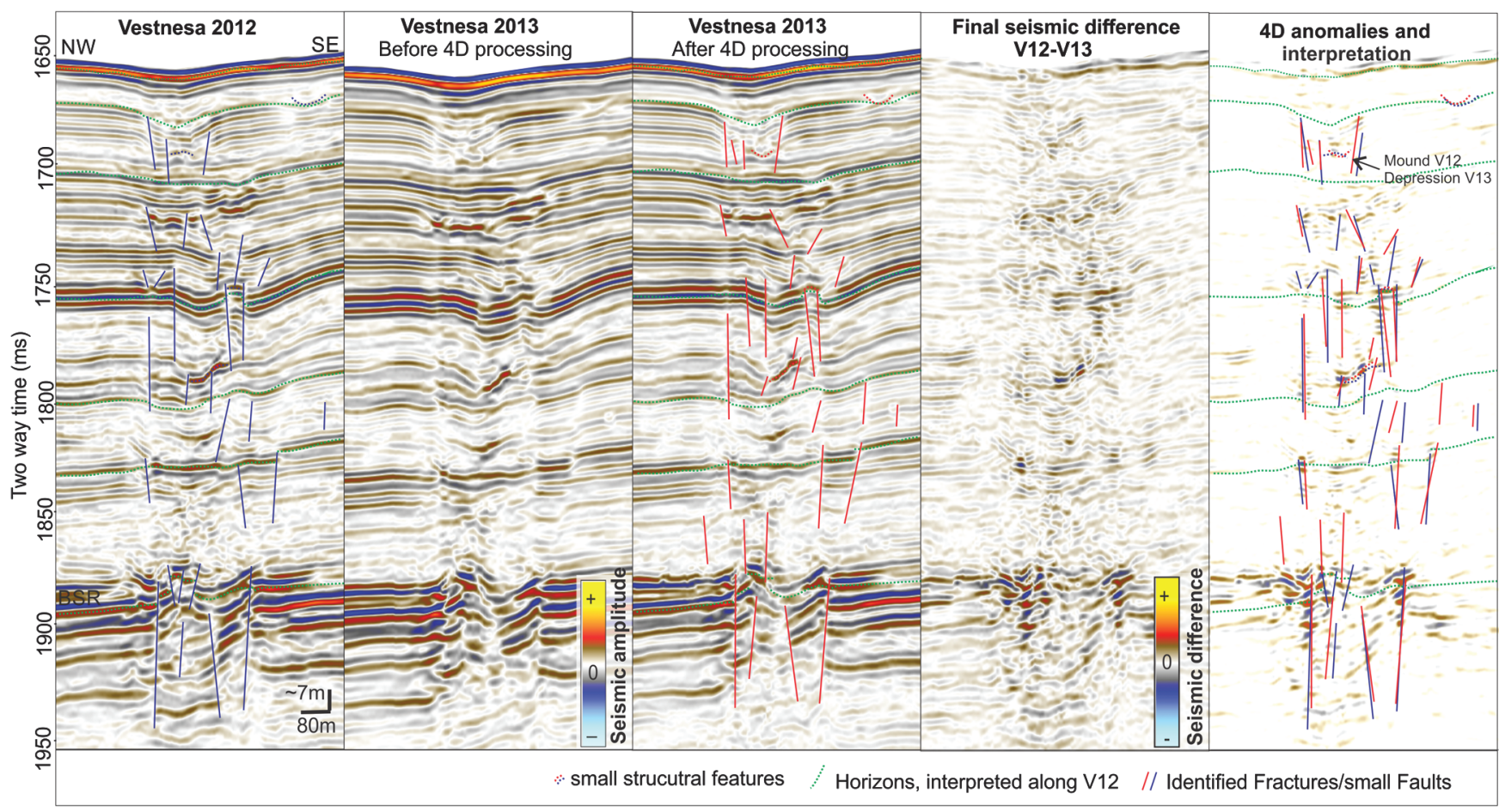

Figure 13. A seismic example of Vestnesa 2012 and 2013 (before and after 4D processing) and the corresponding difference beneath the northeast side of the Torsk pockmark and individual interpretation of fractures/small faults. In the column to the left, interpretation is overlaid on the seismic difference, highlighting the 4D anomalies. 
scale (approximately 3-6 m). We find that the seismic repeatability is strongly geology dependent. In stratified marine sediments, we find that $N$ rms measures comparable with today's 4D seismic $N \mathrm{rms}$ average $(\mathrm{Nrms}=30 \%)$. In glacial sediments and harder sedimentary rocks, we estimate an $\mathrm{Nrms}$ of $30 \%-40 \%$, and in more complex moraine material, the $\mathrm{Nrms}$ level is $70 \%-75 \%$. Important factors that influence the repeatability are accurate repetition of acquisition setup, calm weather, and minimal wave activity as well as sufficient time between each shot (i.e., to minimize noise from the previous shot). At the active fluid flow and gas hydrate system of the Vestnesa Ridge, we obtain high $\mathrm{Nrms}$ in gas chimneys and low $\mathrm{Nrms}$ outside gas chimneys. Moreover, we observe high $\mathrm{Nrms}$ in the shallow subsurface below active pockmarks (bubbles rising from the seafloor and elevated methane concentrations) and low Nrms in the shallow part beneath passive pockmarks (no bubbles are observed, and there are lower methane concentrations). We suggest that these observations indicate detection of real 4D anomalies related to fluid flow, which we find promising for potential future 4D investigations of fine-scaled geology and fluid-related differences. The ability to resolve fluid related changes on a very fine scale may open up new vistas for industrially and academically oriented gas hydrate and fluid-flow communities.

\section{ACKNOWLEDGMENTS}

The project is funded by VISTA - a basic research program in collaboration between the Norwegian Academy of Science and Letters and Statoil. The research is also a part of the Centre for Arctic Gas Hydrate, Environment, and Climate and was supported by the Research Council of Norway through its Centres of Excellence funding scheme grant no. 223259. We further thank the crew and scientists on board the RV Helmer Hanssen for assistance in acquiring the seismic data on the various cruises, and we thank DECO Geophysical, CGG HampsonRussell, GeoTeric, and Schlumberger for software and support. We thank E. Kragh and two anonymous reviewers for constructive comments and ideas to improve the manuscript.

\section{DATA AND MATERIALS AVAILABILITY}

Data associated with this research are available and can be obtained by contacting the corresponding author.

\section{APPENDIX A}

\section{$f-k$ SPECTRUM TO INVESTIGATE FREQUENCY AND REFLECTOR DEPENDENT 4D NOISE}

Plotting seismic difference in an $f-k$ spectrum is another way to investigate potential relation of seismic frequency and dip of reflections on repeatability (Eiken et al., 2003). Such analysis is, however, insensitive to 4D amplitude strength. To account for that, one might regard the lowest percentage $(10 \%)$ of the amplitudes as background noise and remove these amplitudes before the analysis. The $f-k$ spectrum of the seismic difference between Lyngen 2014 and 2012 indicates that 4D noise tends to be scattered in frequencies ranging between 100 and $200 \mathrm{~Hz}$ in subhorizontal reflector-dip orientations compared to the original spectrum that was vertically centered on flat events (Figure A-1).

\section{APPENDIX B}

\section{RESIDUAL SHOT NOISE CALCULATIONS}

To better understand the apparent noise in the data, we calculated how much it is possible to improve the S/N and thus the 4D quality by reducing the shot rate from 4 to $5 \mathrm{~s}$ by using the equation in Landrø (2008):

$$
\frac{S}{N}=\frac{S}{s(t)+n(t)}=\frac{\frac{P_{1} e^{-\pi f t \div Q}}{t^{2}}+\frac{P_{2}}{t} R_{0}^{\alpha t}}{\frac{P_{1} e^{-\pi f(t+\tau) \div Q}}{(t+\tau)^{2}}+\frac{P_{2}}{(t+\tau)} R_{0}^{\alpha(t+\tau)}+n(t)}
$$

If the noise apparent in the data consists of shot-induced noise $(s)$ and ambient noise $(n)$ at a given recording time $t$ and a shot interval $\tau$, the $\mathrm{S} / \mathrm{N}$ can be calculated from this formula (Landrø, 2008).
Inline $51, \mathrm{f}-\mathrm{k}$ spectrum analysis of $4 \mathrm{D}$ seismic noise

$$
\text { a) }
$$

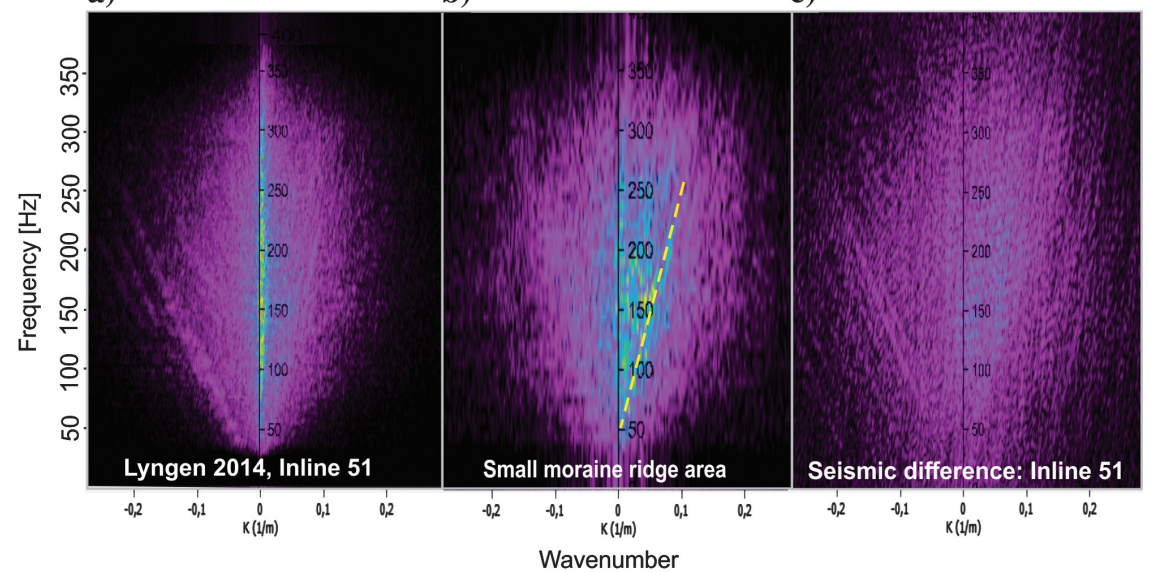

b)

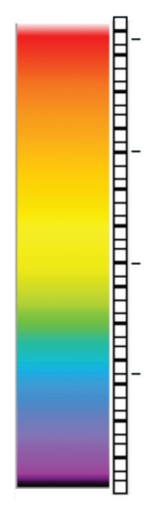

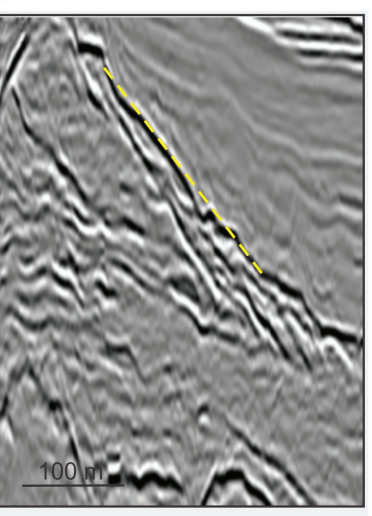

Figure A-1. The $f-k$ spectrum of (a) inline 51 of Lyngen 2014 and the same of (b) a magnification around the moraine ridge area (the area to the right of figure) and of (c) a corresponding seismic difference (the entire inline 51) indicating that 4D anomalies occur more frequently between 100 and $200 \mathrm{~Hz}$ and in scattered dip orientations. Horizontal lying reflections are well-matched. Ten percent of the lowest seismic difference amplitudes are here regarded as "background noise" and clipped off in front of the $f-k$ analysis to visualize this effect. 
The terms $P_{1}$ and $P_{2}$ are the scalars related to the source strength and water level. We used 20,000 and 100, respectively, which are the same values as used in Landrø (2008) (we observe that changing these values does not change the results much). The term $R_{0}$ is the dominant reflection coefficient of the seafloor (usually $0.3-0.4-$ we used 0.3 due to relatively soft sediments), $Q$ is a constant of 80 that represent exponential decay (of energy), and $\alpha$ is a fitting parameter representing the number of multiple reflections - we used 0.5 (experimental value). Finally, $f$ should represent a typical frequency in the data — we used $175 \mathrm{~Hz}$.

From this equation, we calculated a common signal value of 21.19 at $1700 \mathrm{~ms}$ TWT depth. At a shot interval of $4 \mathrm{~s}$, we calculated a shot-induced noise value of $s(4)=0.57$. The corresponding shot-induced $\mathrm{S} / \mathrm{N}$ becomes $(21.19 / 0.567=)$ 37.3. Exchanging the shot interval of $4 \mathrm{~s}$ in the formula with 5 and $6 \mathrm{~s}$ give a new shot-induced noise value of $(s(5)=) 0.264$ and $(s(6)=) 0.126$, respectively. Thus, a $1 \mathrm{~s}$ increase in shot-interval from 4 to $5 \mathrm{~s}$ causes a $53 \%$ decrease in shot-induced noise, and a $2 \mathrm{~s}$ increase, from 4 to $6 \mathrm{~s}$, causes a continued decrease of shot-induced noise by $77 \%$. Because most lines were acquired with a 6s shot interval (average is 5.9), we extend the calculations by assuming that the survey was shot with a 6s shot interval.

Assuming further that the rest of the noise apparent in the data is ambient noise $n(t)$ (e.g., caused by weather) and by use of the true calculated S/N of Vestnesa 2012 and 2013, we infer the ambient noise $n(t)$ in the Vestnesa 2012 to be

$$
\begin{aligned}
\frac{S}{N} & =\frac{S}{s(t)+n(t)}=\frac{S}{x} \rightarrow 12.9=\frac{21.9}{x} \rightarrow x \\
& =1.64 \rightarrow n(t)=1.64-0.567=1.076 .
\end{aligned}
$$

And, in Vestnesa 2013 it is

$$
\begin{aligned}
\frac{S}{N} & =\frac{S}{s(t)+n(t)}=\frac{S}{x} \rightarrow 18.7=\frac{21.9}{x} \rightarrow x \\
& =0.882 \rightarrow n(t)=0.882-0.126=0.756
\end{aligned}
$$

When shooting with a longer time interval, at the same sailing speed, the trace fold (traces in each bin) will be reduced linearly if the average sailing steep remains constant between the surveys. In theory, the increase of the shot rate from 4 to $6 \mathrm{~s}$ causes the true fold of 8.7 in 2012 to be reduced to 5.8 (and from 4 to $5 \mathrm{~s}$ to be reduced to 7.2, which is the actual trace fold of Vestnesa 2013). The data binned with $3.125 \mathrm{~m}$ got a new average trace fold of 2.75 , and we further calculated a new average $\mathrm{S} / \mathrm{N}$ of 15.9. Assuming a linear relationship between the fold and ambient noise, we find this relationship between the noise and the average fold for Vestnesa 2013

$$
n(t)=-0,1146 * \mathrm{FOLD}+1.4832 .
$$

For the Vestnesa 2012 with a fold of 8.7, we achieve an ambient noise value of 0.49 , and for the Vestnesa 2013 with a fold of 7.2, the ambient noise value is 0.62 . This represents a 0.134 difference in the ambient noise level, which might be fold related.

\section{APPENDIX C}

\section{LESSONS LEARNED AND SUGGESTIONS TO IMPROVE HR4D DATA}

We consider a few acquisition- and processing-related factors worth considering prior to potential future comparable time-lapse studies.

A wave gauge could be installed to better correct for static differences between the baseline and repeat(s) related to water level and tide differences, and one should consider calculating individual measures by preferable several CTD stations at the site prior to the acquisition. Furthermore, it is important to be aware of shot-induced noise in deep waters and how to minimize it (a large enough shot interval)

We used a catenary line to calculate the geographical position of each streamer. However, due to, i.e., surface currents, the cross-cable and streamer are not always following a perfect catenary line. Thus, using a polygon-fitted line equation can lead to a more accurate positioning of the data (Crutchley et al., 2011). Not considered in this study $4 \mathrm{D}$ binning is moreover a process that should lead to better repeatability. Finally, a more advanced and accurate velocity model than used in this study can add in a better migration process (e.g., Kirchhoff migration), and thus it should in theory lead to better collapse of diffractions.

\section{REFERENCES}

Andorsen, K., and M. Landro, 2000, Source signature variations versus repeatability: Astudy based on a zero-offset VSP experiment: Journal of Seismic Exploration, 9, 61-72.

Bünz, S., S. Polyanov, S. Vadakkepuliyambatta, C. Consolaro, and J. Mienert,2012, Active gas venting through hydrate-bearing sediments on the Vestnesa Ridge, offshore W-Svalbard: Marine Geology, 332, 189-197, doi: 10.1016/j.margeo.2012.09.012.

Calvert, R.,2005, Insights and methods for 4D reservoir monitoring and characterization: SEG and European Association of Geoscientists and Engineers.

Chadwick, R., R. Arts, and O. Eiken,2005, 4D seismic quantification of a growing CO2 plume at Sleipner, North Sea: Geological Societyof London, Petroleum Geology Conference Series 6, 1385-1399.

Crutchley, G. J., C. Berndt, D. Klaeschen, and D. G. Masson, 2011, Insights into active deformation in the Gulf of Cadiz from new 3-D seismic and high-resolution bathymetry data: Geochemistry, Geophysics, Geosystems, 12, 1525-2027, doi: 10.1029/2011GC003576.

Crutchley, G. J., I. A. Pecher, A. R. Gorman, S. A. Henrys, and J. Greinert,2010, Seismic imaging of gas conduits beneath seafloor seep sites in a shallow marine gas hydrate province, Hikurangi Margin, New Zealand: Marine Geology, 272, 114-126, doi: 10.1016/j.margeo.2009.03.007.

Eiken, O., 2005, Repeatability issues of time-lapse marine seismic data: 9th International Congress of the Brazilian Geophysical Society and EXPOGEF, 11-14.

Eiken, O., G. U. Haugen, M. Schonewille, and A. Duijndam, 2003, A proven method for acquiring highly repeatable towed streamer seismic data: Geophysics, 68, 1303-1309, doi: 10.1190/1.1598123.

Eiken, O., and K. Hinz, 1993, Contourites in the Fram Strait: Sedimentary Geology, 82, 15-32, doi: 10.1016/0037-0738(93)90110-Q.

Eriksen, F. N., M. Assad, O. K. Eriksen, H. H. Stokke, and S. Planke, 2014, HiRes P-cable 3D data for shallow reservoir mapping and geohazard predictions - Case examples from the Barents Sea: Near Surface Geoscience-First Applied Shallow Marine Geophysics Conference, doi: 10 .3997/2214-4609.20142113.

Hansen, O., O. Eiken, S. Østmo, R. I. Johansen, and A. Smith,2011, Monitoring $\mathrm{CO}_{2}$ injection into a fluvial brine-filled sandstone formation at the Snøhvit field, Barents Sea: 81st Annual International Meeting, SEG, Expanded Abstracts, 4092-4096, doi: 10.1190/1.3628061.

Hatchell, P., R. Kamarudin, J. Lopez, S. Bakku, Z. Yang, K. Wang, V. Gee, J. Mestayer, K. King, and A. Kudarova, 2017, Low-cost high-resolution 3D and 4D seismic for deepwater fields: 87th Annual International Meeting, SEG, Expanded Abstracts, 5782-5786, doi: 10.1190/segam201717723832.1 . 
Ivanova, A., A. Kashubin, N. Juhojuntti, J. Kummerow, J. Henninges, C. Juhlin, S. Lüth, and M. Ivandic, 2012, Monitoring and volumetric estimation of injected $\mathrm{CO}_{2}$ using 4D seismic, petrophysicaldata, core measurements and well logging: A case study at Ketzin, Germany: Geophysical Prospecting, 60, 957-973, doi: 10.1111/j.1365-2478.2012 .01045.x.

Johnston, D. H., 2013, Practical applications of time-lapse seismic data: SEG.

Knies, J., M. Daszinnies, A. Plaza-Faverola, S. Chand, Ø. Sylta, S. Bünz, J. E. Johnson, R. Mattingsdal, and J. Mienert, 2018, Modeling persistent methane see page offshore western Svalbard since early Pleistocene: Marine and Petroleum Geology, 91, 800-811, doi: 10.1016/j.marpetgeo.2018.01.020.

Kragh, E., and P. Christie, 2002, Seismic repeatability, normalized rms, and predictability: The Leading Edge, 21, 640-647, doi: 10.1190/1.1497316.

Landrø, M.,1999, Repeatability issues of 3-D VSP data: Geophysics, 64, 1673-1679, doi: 10.1190/1.1444671.

Landrø, M.,2008, The effect of noise generated by previous shots on seismic reflection data: Geophysics, 73, no. 3, Q9-Q17, doi: 10.1190/1.2894453.

Landrø, M., and L. Amundsen, 2018, Introduction to exploration geophysics with recent advances: Bivrost Geo.

Landrø, M., O. A. Solheim, E. Hilde, B. O. Ekren, and L. K. Strønen, 1999 The Gullfaks 4D seismic study: Petroleum Geoscience, 5, 213-226, doi: 10.1144/petgeo.5.3.213.

Lecerf, D., J. Burren, E. Hodges, and C. Barros, 2015, Repeatability measure for broadband 4D seismic: 85th Annual International Meeting, SEG, Expanded Abstracts, 5483-5487, doi: 10.1190/segam2015-5927745.1.

Liu, G., S. Fomel, L. Jin, and X. Chen, 2009, Stacking seismic data using local correlation: Geophysics, 74, no. 3, V43-V48, doi: 10.1190/1 .3085643 .

Lumley, D. E.,2001, Time-lapse seismic reservoir monitoring: Geophysics, 66, 50-53, doi: 10.1190/1.1444921.

Malme, T. N., M. Landrø, and R. Mittet, 2005, Overburden distortions Implications for seismic AVO analysis and time-lapse seismic: Journal of Geophysics and Engineering, 2, 81-89, doi: 10.1088/1742-2132/2/2/001.

Misaghi, A., M. Landrø, and S. A. Petersen, 2007, Overburden complexity and repeatability of seismic data: Impacts of positioning errors at the Oseberg field, North Sea: Geophysical Prospecting, 55, 365-379, doi: 10.1111/j.1365-2478.2007.00620.x.

Nasser, M., S. Ronen, and J. Stammeijer, 2016, Introduction to this special section: 4D seismic: The Leading Edge, 35, 828-830, doi: 10.1190/ tle35100828.1.

Osdal, B., S. Grude, and M. Landrø, 2010, Sea bed diffraction and impact on 4D seismic data - Observations from synthetic modeling and field data: 72nd Annual International Conference and Exhibition, EAGE, Extended Abstracts, doi: 10.3997/2214-4609.201400834.

Panieri, G., S. Bünz, D. J. Fornari, J. Escartin, P. Serov, P. Jansson, M. E. Torres, J. E. Johnson, W. Hong, and S. Sauer, 2017, An integrated view of the methane system in the pockmarks at Vestnesa Ridge, $79^{\circ} \mathrm{N}$ : Marine Geology, 390, 282-300, doi: 10.1016/j.margeo.2017.06.006.

Petersen, C., S. Bunz, S. Hustoft, and J. Mienert, 2008, 3D seismic imaging of marine gas hydrates in Arctic sediments of the Vestnesa Ridge off the W-Svalbard margin: Proceedings of the 6th International Conference on Gas Hydrates, 6-10.

Petersen, C. J., S. Bünz, S. Hustoft, J. Mienert, and D. Klaeschen, 2010, High-resolution P-cable 3D seismic imaging of gas chimney structures in gas hydrated sediments of an Arctic sediment drift: Marine and Petroleum Geology, 27, 1981-1994, doi: 10.1016/j.marpetgeo.2010.06 .006 .

Pevzner, R., V. Shulakova, A. Kepic, and M. Urosevic, 2011, Repeatability analysis of land time-lapse seismic data: $\mathrm{CO}_{2} \mathrm{CRC}$ Otway pilot project case study: Geophysical Prospecting, 59, 66-77, doi: 10.1111/j.13652478.2010.00907.x.

Planke, S., 2013, P-cable high-resolution 3D seismic imaging of gas hydrates and shallow gas: 75th Annual International Conference and Exhibition, EAGE, Extended Abstracts, doi: 10.3997/2214-4609.20131167.

Planke, S., F. N. Eriksen, C. Berndt, J. Mienert, and D. Masson, 2009 P-cable high-resolution seismic: Oceanography, 22, 85, doi: 10.5670/ oceanog.

Plaza-Faverola, A., S. Bünz, and J. Mienert, 2011, Repeated fluid expulsion through sub-seabed chimneys offshore Norway in response to glacial cycles: Earth and Planetary Science Letters, 305, 297-308, doi: 10 .1016/j.eps1.2011.03.001.

Smith, A. J., J. Mienert, S. Bünz, and J. Greinert2014, Thermogenic methane injection via bubble transport into the upper Arctic Ocean from the hydrate-charged Vestnesa Ridge, Svalbard: Geochemistry, Geophysics, Geosystems, 15, 1945-1959, doi: 10.1002/2013GC005179.

Sztybor, K., and T. L. Rasmussen, 2017, Diagenetic disturbances of marine sedimentary records from methane-influenced environments in the Fram Strait as indications of variation in seep intensity during the last 35000 years: Boreas, 46, 212-228, doi: 10.1111/bor.12202.

Tasianas, A., I. Martens, S. Bünz, and J. Mienert, 2016, Mechanisms initiating fluid migration at Snøhvit and Albatross fields, Barents Sea: Arktos, 2 26, doi: 10.1007/s41063-016-0026-z.

Vedanti, N., and M. K. Sen, 2009, Seismic inversion tracks in situ combustion: A case study from Balol oil field, India: Geophysics, 74, no. 4 B103-B112, doi: 10.1190/1.3129262. 